\title{
Organic and Inorganic Fouling in Heat Exchangers - Industrial Case Study: Analysis of Fouling State
}

\author{
E. Diaz-Bejarano ${ }^{1,3}$, E. Behranvand ${ }^{2}$, F. Coletti ${ }^{3}$, M. R. Mozdianfard ${ }^{2}$, and S. Macchietto ${ }^{1,3 *}$ \\ ${ }^{1}$ Department of Chemical Engineering, Imperial College London, London SW7 2AZ, UK \\ ${ }^{2}$ Chemical Engineering Department, Engineering Faculty, University of Kashan, Ghotb-e-Ravandi \\ Bolvd., Kashan, Iran
}

${ }^{3}$ Hexxcell Ltd., Imperial College Incubator, Bessemer Building Level 2, Imperial College London, London SW7 2AZ, UK,

KEYWORDS: crude oil, fouling, inorganics, heat exchanger, monitoring, diagnosis, troubleshooting.

\begin{abstract}
A comprehensive model-based thermo-hydraulic methodology is used to investigate fouling behaviour in post-desalter pre-flash drum refinery heat exchangers, where high concentration of inorganics in the deposits was reported. The method combines a data-driven analysis of plant measurements (tube-side pressure drop in addition to typical temperatures and flowrates) with a modelbased analysis using advanced dynamic thermo-hydraulic models of shell-and-tube heat exchangers undergoing fouling. A deposit model capable of tracking composition and deposition history was extended to include thermal-conductivity mixing models appropriate for various deposit structures. The results demonstrate that substantial new information can be extracted from the plant measurements, in particular: the detailed fouling state of the exchangers, the thickness and effective conductivity of the deposits, as well as the radial conductivity and composition profiles of the deposits, reflecting the exchanger operation history. It is shown that episodes of rapid and acute fouling, and deposition of inorganic materials could be identified and quantified. Deposit samples were collected at the end of run and analysed for composition, including radial profiles, using SEM-EDX. A validation of the approach
\end{abstract}


was carried out by i) a comparison of averaged predicted and experimental inorganic weight fractions in a mixed deposit sample, and ii) an initial comparison of predicted and experimental radial inorganics profiles in deposits from similar exchangers. Both steps yielded surprisingly good agreement. The case study results demonstrate the benefits that could be achieved in industrial practices by studying fouling as a multi-component system while using both temperature and pressure drop measurements plant data. The study indicates that the method employed represents a new powerful, model-based analysis tool for monitoring, diagnosis and troubleshooting of fouling in heat exchangers.

\section{Introduction}

Fouling in the preheat train (PHT) of crude distillation units (CDUs) not only imposes a major cost in oil refineries in terms of energy losses and fuel consumption but also impacts emission of greenhouse gases and continuity of operations [1]. It has been estimated that fouling mitigation in CDUs could save $15 \%$ in fuel consumption of the furnace downstream the PHT, equivalent to worldwide crude oil savings of about 500,000 bbl/day [2], the size of a large refinery.

Monitoring of fouling, accurate diagnosis of its causes, and reliable prediction of its effects are important in assessing a PHT network performance and are essential pre-requisites to identifying mitigation opportunities [3-9]. Established methodologies typically focus on the thermal effects produced by the deposition of low conductivity materials on the heat transfer surfaces, monitored using temperature measurements. Semi-empirical models that attempt to capture fouling as a function of process conditions and time (such as those by Ebert and Panchal $[10,11]$ ) are usually fitted to calculated values of the fouling thermal resistance, $R_{f}$, (or the rate of change in fouling resistance) [12-16], a quantity that is derived from primary measurements and typically subject to many simplifying assumptions (e.g. lumped heat exchanger models, constant physical properties, etc.). These classic methodologies have been severely criticised in the past [17-19] but are still largely used. Efforts to improve the accuracy (e.g. [20]) include for example variants in the calculation of $R_{f}[6,21,22]$, and the application of smoothing [23] or filtering techniques [24]. Nevertheless, this approach to fouling monitoring and prediction retains serious limitations because of the inherent inability of $R_{f}$-based indicators to describe the extent, location, nature and history of the deposit. 
$R_{f}$ does not directly provide information on the increase in pressure drop under fouling conditions. Fouling build-up affects pressure drop in various ways depending on the type and nature of deposit and operating conditions, through changes in roughness (surface morphology), viscoelastic properties of the deposit, constriction of the flow section as the layer builds up, and local blockage due to flow maldistribution within each tube pass [13, 25-27]. Furthermore, the flow constriction is not uniform, but follows the distribution of the local deposit thickness $\left(\delta_{l}(\mathrm{z})\right)$ in the axial direction along a tube and through the various passes, resulting from variation of the fouling rate with the operating conditions (e.g. temperature or shear stress) and concentration of fouling precursors. Fully (axially and radially) distributed models are required to adequately capture these effects, especially considering the fact that excessive pressure drop is a common reason for taking heat exchangers off line for cleaning [28].

Also, an increase (or decrease) in $R_{f}$ does not necessarily correlate to deposit growth (or removal), as it may also result from changes in the deposit thermal conductivity. Deposit thermal conductivity typically varies at any axial and radial point in a heat exchanger tube, depending on: a) local composition, a function (like rings in a tree) of deposition history; b) deposit morphology, i.e. its microstructure and porosity; c) transformations over time, due for instance to ageing, which also depends on operating history. Consequently, the deposit thermal conductivity provides an indirect measure of the deposit composition and its evolution. The characterization of fouling in terms of a simple $R_{f}$ does not reflect the above and may lead to misinterpretation of the current fouling state of an exchanger, to misinterpretation of variations in the deposit composition-ageing as growth or removal, to wrong diagnosis of the underlying causes and to incorrect choice of fouling mitigation strategies [29, 30].

To monitor fouling effectively in heat exchangers and reliably predict its effects, it is necessary to evaluate both its thermal and hydraulic aspects. This requires characterization of the deposit thickness and thermal conductivity in different parts of the exchanger, over time. Understanding this would both bring invaluable insights into the underlying causes, and lead to more reliable forward predictions. Conversely, if both thermal and hydraulic measurements (e.g. temperatures, flowrates and pressure drops) are available, it should be possible to solve the inverse problem and infer those two properties. The use of thermo-hydraulic measurements in combination to estimate deposit's conductivity is not a 
new concept. For example, Watkinson [31] estimated the thermal-conductivity, $\lambda$, of crude oil fouling deposits using thermo-hydraulic measurements in controlled experiments in a single tube and reported an average value $\lambda \approx 0.3 \mathrm{~W} / \mathrm{mK}$. In later publications [32,33] the same author recommended values for hydrocarbon deposits ranging from 0.15 to $0.25 \mathrm{~W} / \mathrm{mK}$ for fresh deposits and up to $1 \mathrm{~W} / \mathrm{mK}$ for significantly aged deposits. These values were used subsequently in several publications (e.g. [2, 4, 13, 34-38] as representatives of deposits composed mainly of organic matter. However, as discussed elsewhere [30], crude oil fouling deposits often contain significant proportions of inorganics, with fractions of $15-80_{\mathrm{wt}} \%$ reported in multiple field and laboratory studies [17, 39-45]. Such inorganic deposits are characterized by a thermal conductivity $\lambda=[1-5] \mathrm{W} / \mathrm{mK}$, up to 10 times higher than organic matter. Ignoring the presence of inorganic material may therefore lead to significant errors in assessing the thermo-hydraulic performance of heat exchangers. Furthermore, the presence of inorganics typically indicates fouling mechanisms different from chemical reaction fouling, the mechanism usually accepted as dominant in crude oil fouling $[1,12]$ and is often linked to equipment malfunction (e.g. desalter) and corrosion. Establishing their presence is therefore important.

Unfortunately, deposit composition cannot be readily measured during operation and can be obtained only via analytical characterization of the deposits after refinery shut-down by dismantling of heat exchangers, extracting tube bundles and sampling. The combined use of thermo-hydraulic measurements with model-based analysis to infer the deposit thickness and conductivity represents an alternative way to back-calculate the composition of deposits formed in heat exchangers and their evolution over time. This is the subject of this paper.

This approach relies on (i) detailed thermo-hydraulic models capable of capturing the dynamics of fouling deposition, the evolving deposit characteristics and their effect on measurable performance; and (ii) primary data of sufficient quality comprising temperature, flowrate and pressure drop measurements. For validation purposes, it is necessary to have some composition data of crude oils and fouling deposits.

In this paper, the detailed modelling framework and thermo-hydraulic analysis methodology presented by Diaz-Bejarano et al. [46] was applied to a comprehensive industrial case study, where all 
such information were available. The method, for the analysis of individual shell-and-tube heat exchangers, consists of two main steps:

a) A data-driven analysis of the exchanger fouling state, starting from a time series of thermohydraulic plant measurements. This step determines extent, characteristics (thermal conductivity and composition) and evolution of the deposit and the corresponding fouling rates over time, for fouling monitoring and diagnosis purposes;

b) A model-based analysis of these fouling rates, to identify and fit suitable deposition models that can be used for performance prediction purposes, and performance improvement studies such as cleaning scheduling.

The paper focuses on the first step, highlighting the insights that can be produced about the fouling state of an exchanger, the likely fouling mechanism(s) and useful diagnostic information that can be inferred regarding causes and events leading to the deposits. The analysis of the fouling rate for this case study (i.e. step b) will be discussed in a companion paper.

In a previous industrial case study [46] pressure drop measurements were not available and the models were used as "soft pressure drop sensors" to identify suitable deposit conductivities and help in model identification. Here, for the first time, the full methodology is applied to an industrial case study where pressure drop measurements were also available. The study is based on the comprehensive set of refinery field data over a long period reported by Mozdianfard and Behranvand [43, 44], which include tube-side pressure drop measurements and end-of run compositional analysis of the deposits, as well as the usual flowrate and temperature measurements. The case study focuses on the post-desalter, preflash drum heat exchanger (PDPF), the unit most adversely affected by fouling out of those studied by Mozdianfard and Behranvand [43, 44].

The paper is organised as follows: First, a summary is presented in section 2 of the basic thermohydraulic heat exchanger model used. Several models for linking conductivity and composition for deposits formed by organic and inorganic components are presented in section 2.2 , followed by a summary of the thermo-hydraulic analysis method in section 3. A description of the refinery exchanger considered is presented in section 4, together with the data for 1256 days of operation, and composition results on the fouling deposit collected and analysed at the end of the run. Application of the method 
for inferring the thermal conductivity deposition history is then detailed, followed by estimation of the corresponding deposit composition history. Experimental composition analysis of some deposits collected in the refinery at the end-of-run, and a comparison of the measured and estimated deposit composition history profiles are presented in section 4.5 , followed by some concluding notes.

\section{Modelling Framework}

The modelling framework used, schematically shown in Figure 1, brings together the dynamic, distributed shell-and-tube heat exchanger model by Coletti and Macchietto [2] as implemented in Hexxcell Studio ${ }^{\mathrm{TM}}$ [47] and the multi-component deposit model by Diaz-Bejarano et al. [35], which is capable of tracking the deposit's composition history. Various simplifications of the deposit model, referred to as Modes, are used as described in [40]. The configuration used here assumes fouling to be limited to the inside of the tubes, as justified by the data. However, shell-side fouling could also be considered if needed as discussed in more details elsewhere [48].

\subsection{Heat exchanger model}

The shell-and-tube heat exchanger model is dynamic and 2D distributed in space, with several interconnected spatial domains: tube-side $\left(\Omega_{t}\right)$, shell-side $\left(\Omega_{s}\right)$, tube wall $\left(\Omega_{w}\right)$ and fouling layer $\left(\Omega_{l}\right)$. The reader is referred to ref. [2] for a full description of the model equations. In the framework used here, the original deposit model [2] is substituted with the ones explained below. The main equations in the heat exchanger model are summarized in Table 1.

\subsection{Deposit Modes}

Two modes of the deposit model [40] are used:

Mode I - Distributed, multi-component: this formulation of the deposit follows a reaction engineering approach and captures the detailed time-conditions history at each point in the layer by including multicomponent species, chemical reactions (if any) and fluxes at a moving oil/deposit boundary. The model is dynamic, distributed in the axial and radial directions, and considers explicitly the local concentration of fouling species, which eventually determine the local physical properties of the deposit such as thermal conductivity. 
The two main equations describing the deposit model in Mode I are the heat and energy balances which, after a Lagrangian transformation in the radial direction, are given by Eqs. (1) and (2):

$$
\begin{gathered}
\left(\frac{\partial c_{l, i}\left(z, \tilde{r}_{l}\right)}{\partial t}-\frac{\tilde{r}_{l}}{\delta_{l}(z)} \dot{\delta}_{l}(z) \frac{\partial c_{l, i}\left(z, \tilde{r}_{l}\right)}{\partial \tilde{r}_{l}}\right)=\sum_{j=1}^{N R} v_{i j} r_{j}\left(z, \tilde{r}_{l}\right) \\
\rho_{l}\left(z, \tilde{r}_{l}\right) C_{p, l}\left(z, \tilde{r}_{l}\right)\left(\frac{\partial T_{l}\left(z, \tilde{r}_{l}\right)}{\partial t}-\frac{\tilde{r}_{l}}{\delta_{l}(z)} \dot{\delta}_{l}(z) \frac{\partial T_{l}\left(z, \tilde{r}_{l}\right)}{\partial \tilde{r}_{l}}\right)=\frac{1}{\left(R_{i}-\tilde{r}_{l} \delta_{l}(z)\right) \delta_{l}(z)^{2}} \frac{\partial}{\partial \tilde{r}_{l}}\left(\left(R_{i}-\right.\right. \\
\left.\left.\tilde{r}_{l} \delta_{l}(z)\right) \lambda_{l}\left(z, \tilde{r}_{l}\right) \frac{\partial T_{l}\left(z, \tilde{r}_{l}\right)}{\partial \tilde{r}_{l}}\right)
\end{gathered}
$$

where $c_{l, i}$ is the mass concentration of component $i, T_{l}$ temperature, $\delta_{l}$ the deposit layer thickness, $\dot{\delta}_{l}$ the rate of change in thickness, $r_{j}$ the rate of reaction $j, t$ time, $z$ the axial coordinate, $\rho_{l}$ density, $C_{p, l}$ specific heat capacity, and $\lambda_{l}$ thermal conductivity of the mixture at each point $\left(\mathrm{z}, \tilde{r}_{l}\right)$. The dimensionless radial coordinate, $\tilde{r}_{l}$, is calculated as:

$$
\tilde{r}_{l}=\frac{R_{i}-r}{\delta_{l}}
$$

where $r$ is the dimensional radial coordinate and $R_{i}$ is the tube inner radius.

The boundary condition of the mass balance at the deposit surface corresponds to the concentration of the fresh material depositing on top of the older deposit layer. The model relates the evolution inside the layer to processes occurring at its boundary and allows carrying out seamless simulation of deposit growth and partial removal of heterogeneous deposits - either by shear [29] or by cleaning [46] - and foulant composition changes [30]. This feature is used to trace-back the deposition history and infer the layering of the deposit, as demonstrated in this paper.

Mode II - Uniform thickness and thermal conductivity: this is a simplified version of Mode I that assumes uniform thickness and conductivity through the unit. The mass balance (Eq. 1) is no longer necessary, but the heat balance (Eq. 2) still applies.

\subsection{Linking Deposit Conductivity to Composition: Mixing Models}

To link the deposit composition and morphology to its thermal-conductivity, a suitable thermalconductivity structural model $[49,50]$ is necessary. Many experimental studies exist, for example, for coal-ash deposits in fired boilers [51-53], for which two-phase models for the gas-solid system provide 
good prediction of the conductivity (within 20\%) [54]. As far as we are aware, such comprehensive studies do not exist in published literature on crude oil fouling. However, suitable mixing rules may be used.

The simplest mixing rule is the weighted average based on volume fraction (also called linear or parallel model). In this paper, the deposit is considered to comprise of two phases, one organic and one inorganic (the latter representing the overall contribution of all inorganic species). For such a system the linear mixing model takes the form of Eq. 4. Alternatively, the structure of mixed organic-inorganic crude oil fouling deposits formed under certain conditions may comprise inorganic particles entrapped in a continuous organic medium $[44,55]$. Out of different models for heterogeneous materials identified in the literature [50], the conductivity of such structure may be described by a Maxwell-Eucken (ME) model, which considers two phases, one dispersed and one continuous. The inorganic portion is assumed as the dispersed phase and the organic portion as the continuous phase (Eq. 5). Figure 2 shows the thermal conductivity for binary mixtures of model organic and inorganic pseudo-components (the assumptions involved are discussed later). With ME, the organic phase surrounds the inorganic particles, therefore diminishing the conductivity enhancement due to the presence of the inorganics. The linear model gives more weight to the inorganics, leading to greater conductivity than the ME model. The results with two other structural models, which provide intermediate values between the linear and ME models, are also displayed in Figure 2. The Effective Media Theory (EMT) (Eq. 6) describes mutually dispersed phases, while the Co-Continuous model (CC) (Eq. 7) describes all phases as continuous. As shown in Figure 2, CC gives values close to the linear model for low inorganic content and close to the ME model for high inorganic content. EMT shows the opposite behaviour. The choice of model clearly has a significant impact on the conductivity of a mixture, and therefore attention should be paid to the experimental characterization of deposits to identify the components, the phases and their arrangement in the deposit structure.

Linear

$$
\lambda_{l}\left(z, \tilde{r}_{l}\right)=x_{l, o r g} \lambda_{\text {org }}+x_{l, \text { inorg }} \lambda_{\text {inorg }}
$$

ME

$$
\lambda_{l}\left(z, \tilde{r}_{l}\right)=\frac{x_{l, \text { org }} \lambda_{\text {org }}+x_{l, \text { inorg }} \lambda_{\text {inorg }} \frac{3 \lambda_{\text {org }}}{2 \lambda_{\text {org }}+\lambda_{\text {inorg }}}}{x_{l, \text { org }}+x_{l, \text { inorg }} \frac{3 \lambda_{\text {org }}}{2 \lambda_{\text {org }}+\lambda_{\text {inorg }}}}
$$


EMT

$$
\begin{gathered}
0=x_{l, \text { org }} \frac{\lambda_{\text {org }}-\lambda_{l}\left(z, \tilde{r}_{l}\right)}{\lambda_{\text {org }}+2 \lambda_{l}\left(z, \tilde{r}_{l}\right)}+x_{l, \text { inorg }} \frac{\lambda_{\text {inorg }}-\lambda_{l}\left(z, \tilde{r}_{l}\right)}{\lambda_{\text {inorg }}+2 \lambda_{l}\left(z, \tilde{r}_{l}\right)} \\
\lambda_{l}\left(z, \tilde{r}_{l}\right)=\frac{\sqrt{1+8\left(x_{l, \text { org }} \lambda_{\text {org }}+x_{l, \text { inorg }} \lambda_{\text {inorg }}\right)\left(x_{l, \text { org }} / \lambda_{\text {org }}+x_{l, \text { inorg }} / \lambda_{\text {inorg }}\right)}-1}{2\left(x_{l, \text { org }} / \lambda_{\text {org }}+x_{l, \text { inorg }} / \lambda_{\text {inorg }}\right)}
\end{gathered}
$$

In deposit Mode I, the above conductivity mixing models are applied locally, i.e. the conductivity at each point is a function of the local composition along the radial and axial directions (hence the dependence $\left(z, \tilde{r}_{l}\right)$ in Eqs. 4-7). The deposit is characterized by concentration profiles of multiple species which combine to give radial thermo-conductivity profile. At each location $z$ in the axial direction, an effective conductivity is defined as the value that results in the same overall heat transfer resistance achieved with the actual radially distributed profile:

$$
\lambda_{\text {eff }, n}(z)=\frac{\left.q_{w, n}^{\prime \prime}\right|_{r=R_{i}}(z) R_{i} \ln \left(\frac{R_{i}}{R_{\text {flow }}(z)}\right)}{\left(\left.T_{l, n}\right|_{r=R_{\text {flow }}}(z)-\left.T_{l, n}\right|_{r=R_{i}}(z)\right)}
$$

Similarly, an average thickness and average effective conductivity of the deposit are defined for a heat exchanger overall, and calculated by integrating their respective local values over the tube length and averaging for the number of passes, as described in [46].

In Mode II, the conductivity is assumed constant and uniform throughout the deposit and, therefore, there is no need to define an effective deposit conductivity.

\subsection{Solution types}

The modelling framework allows choosing among various "solution types" for different applications, corresponding to different levels of accuracy in the description of the deposit layer and selection of the degrees of freedom [46]. The solution types are classified in two main categories:

a) "Analysis" types: the fouling deposit characteristics are calculated from measured inlet and outlet conditions (temperature and flowrate and, when available, pressure drop).

b) "Prediction" types: the thermo-hydraulic performance of the heat exchanger is calculated as function of inlet conditions and deposit characteristics. The deposit characteristics may be fixed or time-varying according to the selected deposition model. 
"Analysis" solution types are used here in the refinery case study. "Prediction" solution types will be demonstrated in a companion paper.

\section{Thermo-hydraulic Analysis Method}

The thermo-hydraulic analysis method by Diaz-Bejarano et al. [46] comprises six steps:

1) System definition

2) Data filtering and error analysis

3) Dynamic analysis of fouling state

3a. Apparent Deposit Thickness and Conductivity

3b. Deposit composition layering

4) Selection of deposition rate model

5) Estimation and testing of fouling parameters

6) Analysis of cleanings

Steps 1-3 are applied to the industrial case study in section 4 (steps 3-6 belong to the "prediction" analysis, to be dealt with in the companion paper). Some comments are made in the following on the two stages of Step 3: analysis of fouling state to estimate deposit effective thickness and conductivity profiles (step 3a), and corresponding deposit composition layering profiles (step 3b).

\section{Step 3a. Apparent Deposit Thickness and Conductivity:}

A Mode II model is used in Analysis solution type to infer the deposit's thickness and conductivity over time as a function of the measured inlet conditions data series (temperature and flowrates, tubeside pressure drop, and heat duty calculated from the primary measurements). The deposit's characteristics estimated with this model are referred to as apparent as they include the overall contribution of the spatially distributed deposit layer, errors in the primary measurement used and potential errors arising from mismatches between the mathematical description and the actual system.

The model used at this stage considers a spatially uniform solid deposit with fixed roughness. The apparent deposit thickness $\left(\delta_{l}\right)$ obtained accounts for all variations in the pressure drop resulting from fouling build-up, the main component of which is flow restriction due to growth/reduction of the layer. Roughness dynamics is suspected to be relevant only at the early stages of fouling build-up and flow 
area constriction to be the dominant effect at industrial time-scales $[26,56,57]$, even for very rough crystal deposits [25].

The apparent deposit conductivity $\left(\lambda_{a}\right)$ captures the overall contribution of the local conductivity in the radial and axial direction $\left(\lambda_{l}(\mathrm{z}, \mathrm{r})\right)$ resulting from deposition of different species (i.e. deposition history) and/or their physico-chemical transformations (e.g. ageing). The apparent conductivity obtained this way neglects shell-side fouling. Suitable modifications may be applied if shell-side fouling exists, otherwise the apparent tube-side conductivity may be underestimated.

\section{Step 3b. Deposit composition layering}

A Mode I model is used in Analysis solution type to calculate the radial profiles of the layer conductivity and compositions. The thickness and effective conductivity of the deposit over time are used as inputs while the local conductivity of the fresh deposit at each time that matches the inputs is calculated. This is performed by equating the calculated effective quantities (Eq. 8) to the corresponding apparent values obtained in the previous step (3a). The local radial thermal-conductivity profile is therefore reconstructed using the full time-series of apparent conductivity and thickness throughout the operation period. The resulting rather complex numerical problem is nonetheless efficently solved.

For simple compositional systems, such as binary mixtures, the local conductivity profile may be used to calculate matching composition profiles. This is possible if the conductivity of the indiviudal species is known and a suitable thermal-conductivity mixing model has been identified. For the case study in this paper, the following assumptions (discussed later) were selected:

a) Concentration only varies in the radial direction.

b) There are two pseudo-components, one organic and one inorganic in the deposit mixture.

c) The thermal conductivity of each component is constant and its value given.

These results can be assessed and verified in practice, by comparing the average concentration of inorganics (and indeed, their radial profiles) inferred from the above analysis of operating data to the analytical characterization of deposits collected at the end of an operating period under study, if such information is available. 


\section{Industrial Case Study}

The case study revisits the field study by Mozdianfard and Behranvand [43, 44], who reported detailed fouling data for several years of operation at EORC refinery. The objectives are a) to demonstrate the type and quality of additional information on the fouling characteristics that can be extracted from standard operating data, based on the dynamic thermo-hydraulic analysis presented in previous sections; b) to detail some composition results obtained from the experimental analysis of fouling deposit samples collected at the end of a run, and c) to compare the results predicted by the numerical analysis of the plant data with the experimental deposits characterisation.

After providing some background on the prior work by Mozdianfard and Behranvand, the first three steps in the method in ref. [46] were applied: 1) system definition; 2) data filtering and error analysis; 3) dynamic analysis of the fouling state.

In particular, this study focused on the post-desalter, pre-flash drum (PDPF) exchanger E155AB, the unit most adversely affected by fouling in the field study $[43,44]$. The set of plant data used in the analysis covered 1256 days of operation between two major shutdowns and after a structural change to the network, aimed at increasing the coil inlet temperature and reducing fouling in E155AB. During this period, pressure drop, temperature and flowrate measurements were recorded. Tube-side pressure drops were measured to monitor the progression of fouling in this unit due to its high hydraulic impact. This is an example where hydraulic performance limitations, as opposed to thermal ones, were the driving factor. Figure 3 depicts the network configuration after the overhaul, the location of temperature and pressure drop measurements, and a timeline including the two shutdowns and the period considered (1256 days between the $1^{\text {st }}$ and $2^{\text {nd }}$ shutdown). During the $1^{\text {st }}$ shutdown all exchangers were cleaned. Fouling deposits from E155AB formed during the period considered were collected during the $2^{\text {nd }}$ shutdown.

\subsection{Deposit appearance and analysis}

The deposits collected during the $2^{\text {nd }}$ shutdown are shown in Figure 4 and their chemical analysis and observed characteristics are detailed in Table 2. Further information on the experimental analysis methods used is reported in refs. $[44,58]$. The tubes in the E155AB exchangers were reported to be 
heavily blocked. A thin layer of fouling on the outside surface of the tubes (shell-side fouling) was also reported. The analysis of the tube-side deposit collected revealed mixed organic and inorganic depositions, with an average inorganic content of $58.6 \mathrm{wt} \%$ (mainly inorganic salts and iron sulphide). The shell-side deposits contained $70_{\mathrm{wt}} \%$ of inorganics dominated by iron sulphide. The large saline content was taken as indication of either operational malfunctioning of the desalter or injection of water/caustic solutions.

Figure 4(a, b) shows images of deposits scraped from the inside of the tubes of shells E155A and E155B, respectively. Each of these samples was fully mixed during collection and any potential information about deposit stratification was lost. Figure 4(c) shows a layer of deposit from the shellside of the exchanger, where some layering is evident. The tube-side deposits from E155A (Figure 4a) and E155B (Figure 4b) have different appearance. Those from E155B (operating at lower tube-side temperature - in the range $\approx 130-160^{\circ} \mathrm{C}$ ) presented a sludge-like consistency with entrapped particles. The deposit from E155A (operating at higher tube-side temperature - in the range $\approx 160-180^{\circ} \mathrm{C}$ ) presented a wet solid morphology, similar to that of coal and with a wide range of particle sizes, likely due to breakdown of the deposit during scraping.

A heat exchanger equivalent to E155AB, located in a parallel PHT at the same refinery (called 155X) processed the same oil and under similar operating conditions. A slice of a fouled tube from $155 \mathrm{X}$ collected during a shutdown that took place two years after the $2^{\text {nd }}$ shutdown of E155AB (Figure 4d) gives an idea of the likely deposit appearance, thickness and consistency of the fouling deposit inside the E155AB tubes before the samples in Figure 4(a,b) were scraped. The intact deposit inside the tube from E155X shows a very significant occlusion of the cross-sectional area and stratification. The observed deposit thickness was of similar magnitude to that of the tube wall (2.5-3.2 $\mathrm{mm})$.

Mozdianfard and Behranvand [44] identified several likely causes leading to the tube-side fouling deposits previously described, proposed a 6-step mechanism based on the work by Lambourn and Durrieu [59] and suggested that such mechanism could be common in PDPF heat exchangers. Although the proposed mechanism is still to be verified, it suggests a possible deposit structure consisting of inorganic particles dispersed in a continuous organic phase. Such structure could be well represented by a ME conductivity mixing model. 


\subsection{System definition}

The heat exchanger considered, E155AB, comprises two AET type shells, each with two tube passes. The crude oil flows through the tube-side, first into E155B then into E155A. The heating fluid, a vacuum gas oil (VGO), flows through the shell-side, first into E155A. Thus, the coldest and hottest temperatures in both sides are found at the crude oil inlet to 155B and outlet from E155A, respectively. The tube-side temperature varied in the range $130-180^{\circ} \mathrm{C}$. The physical properties $\left(C_{p}, \lambda, \mu, \rho\right)$ of each fluid were calculated as a function of temperature and characteristic parameters (API, MeABP, $v_{\left.38^{\circ} \mathrm{C}\right)}$ using well established correlations for crude oils and their fractions [60]. The crude oil processed did not change much, and therefore its characteristic parameters were considered constant. The main parameters required to describe the exchanger geometry and the oil physical properties are listed in Table 3.

\subsection{Data filtering and reconciliation}

The entire operation period between the two major shutdowns, comprising 1256 days, was analysed. The set of plant data measured include on the tube-side pressure drop, inlet temperature, outlet temperature and flowrate and on the shell-side flowrate and outlet temperature (the latter only reported intermittently with gaps between days of operation). Some of these primary measurements are reported in $[43,44]$.

Data points with gross errors were eliminated, resulting in about $9 \%$ of the measurements being discarded. The shell-side temperatures were then reconciled. The procedure used involved the interpolation of available shell-side outlet temperatures and the reconciliation of inlet shell temperatures by applying a heat balance to the heat exchanger.

\subsection{Dynamic analysis of fouling state}

The performance of the heat exchanger was evaluated throughout the operating period. The heat duty profile in E155AB, calculated using tube-side measurements, is shown in Figure 5(a). Immediately after the first shutdown it was approximately $30 \mathrm{MW}$ and gradually decreased over time to about $9-$ 10 MW after 700 days, a loss of $\sim 70 \%$ of thermal performance. The tube-side pressure drop (Figure $5 \mathrm{~b}$ ) 
showed the inverse trend, increasing gradually from an initial pressure drop of $\sim 1.7$ bar to nearly 4.5 bar, approximately 3 times the initial value. According to field observations, the heat exchanger was completely clean at the beginning of the period. The gradual loss in thermal and hydraulic performance after resuming operation is attributed to fouling build-up. However, the variation of these two indicators was also affected by operating conditions such as flowrates and temperatures. To eliminate the influence of such variables, the apparent characteristics of the deposit were estimated in the following.

\subsubsection{Apparent Fouling Layer Thickness and Conductivity}

This analysis was performed as described in Section 3 - Step 3a, with some preliminary calibrations. A preliminary analysis had indicated that shell-side fouling, although present, represented at most $9 \%$ of the total thermal resistance and neglecting it was deemed a reasonable approximation. The hydraulic base line, i.e. the pressure drop in clean conditions, was adjusted accordingly. An additional pressure drop due to some unaccounted external pressure drop losses (pipe lengths, bends, etc.) was modelled as a number of velocity heads ( $\Delta P_{\text {External }}$ in Table 1), therefore maintaining proportionality with the flowrate. The calculations are not shown here. Further deviations in pressure drop from the hydraulic base-line thus established were assumed to be caused by tube-side fouling.

First, the apparent deposit thickness was calculated at each time. The resulting time profile, shown in Figure 6(a), presents a nearly monotonic increase over time finally tending to a plateau. At the beginning, the apparent thickness is sensitive to the noise in the pressure drop measurement (as pressure drop is barely sensitive to very small deposit thicknesses), leading to some uncertainty in the calculated value and time variation of the thickness. As deposit builds up, however, the calculated thickness becomes less sensitive to measurement noise and both its value and trend could more accurately be estimated.

To reduce the effect of measurement noise, a centred moving average based on 40 points was applied (the number of points was chosen based on a sensitivity analysis). The deviation of the data points in Figure 6(a) from the moving average and a moving standard deviation, $(\sigma)$, were calculated. The moving average is plotted in Figure $6 \mathrm{~b}$, together with the $95 \%$ confidence $( \pm 2 \sigma)$ error bars for data points every 40 days. The apparent thickness curve in Figure 6(b) indicates a generally falling 
deposition rate shape in which several periods can be distinguished: an initial period (up to approx. 100 days) of fast thickness increase; a short period (between approx. 100 and 200 days) of very fast (acute) thickness increase (corresponding to the pressure drop peak observed in Figure 5b); a third period (between 200 and 600 days) of alternating thickness increases and decreases, and a final period characterised by slow tending to very slow deposit growth. The final apparent thickness estimated of $2.74 \pm 0.06 \mathrm{~mm}$ is very well aligned with the fouling thickness observed in E155X $(\approx 2.5-3.2 \mathrm{~mm}$, Table 2).

The profile of the apparent conductivity of the tube-side deposit, calculated as described in Section 3 - Step 3a, is shown in Figure 7a. In the figure, open round points indicate when the shell-side outlet temperature was measured, and diamond shape dark points when the shell outlet temperature was interpolated. The former points were considered to be reliable, whilst the later were deemed subject to greater uncertainty. Based on the reliable data points only, the apparent conductivity decreases over time, from $\lambda_{a} \approx 1.48 \mathrm{Wm}^{-1} \mathrm{~K}^{-1}$ to values of $\lambda_{a} \approx 0.54-0.70 \mathrm{Wm}^{-1} \mathrm{~K}^{-1}$ at the end of the period, with an average $\lambda_{a}=0.93 \mathrm{Wm}^{-1} \mathrm{~K}^{-1}$ throughout the operating period.

Following the same methodology used with the thickness, 40-day centred moving average, error, standard deviation and error bars were calculated (Figure 7b). As expected, the error in the deposit thickness propagates to the thermal-conductivity. The error is very large during the initial stages, but progressively decreases as the deposit builds up. The thermal conductivity is not reported over the initial 50 days as its calculation was initially considered unreliable due to the significant noise in the apparent thickness. The moving average apparent conductivity curve in Figure $7 \mathrm{~b}$ (which includes the interpolated shell-side temperatures) shows an increase during the acute fouling period identified in the deposit thickness analysis, followed by a generally decreasing trend with periods of alternate ups and downs.

Past literature dealing with potential time-variation of the conductivity of crude oil fouling deposits focussed on gradual conductivity increase over time due to ageing of organic deposits [34, 56, 61-68]. Here, however, the apparent conductivity shows an overall decreasing trend over time. Based on the discussion in the introduction, the trends observed in Figure 7 could indicate different fouling behaviour and deposit composition in the sub-periods previously identified, leading to layers with different local 
conductivity. The impact of complex layering structures of different composition on the deposit effective conductivity was anticipated in a previous theoretical study [30]. Other factors might also in principle affect the apparent thermal-conductivity time profile. However, as noted earlier, factors such as roughness dynamics or shell-side fouling are unlikely to be relevant in this case study given the long time-scale considered and the small contribution of shell-side fouling to the overall thermal resistance. While more experimental evidence is no doubt required to understand the contribution of each of the factors above, the results in the following provide support to the deposit composition layering hypothesis.

Assuming that the change in apparent conductivity is due to deposit composition layering, further useful insights into the evolution of the deposit may be obtained by plotting the apparent conductivity against the apparent thickness, using the moving averages calculated for Figures 6 and 7, as indicated by the continuous line in Figure 8. Each $\lambda_{a}-\delta_{a}$ point on the curve accounts for the contribution of all previous deposition history (i.e., of all material between the wall and the apparent thickness) to the apparent conductivity of the deposit at the corresponding time. The evolution of the apparent conductivity captured in Figure 8 gives an idea of the variation of the underlying local conductivity, and therefore composition, as different species settle on top of the older deposit. The continuous curve in Figure 8 indicates an initial conductivity of $0.8-1 \mathrm{Wm}^{-1} \mathrm{~K}^{-1}$, which corresponds to an organic/inorganic mixture. At a deposit thickness of $0.7 \mathrm{~mm}$ (reached after 110 days) the conductivity starts increasing, reaching a maximum value at a thickness of about $1.5 \mathrm{~mm}$ (at 170 days). This portion corresponds to the acute deposition period. From that point onwards, the conductivity decreases to values of about $0.6-0.7 \mathrm{Wm}^{-1} \mathrm{~K}^{-1}$, indicating an increasing proportion of low-conductive organic matter being deposited.

Although this information is already useful, it is only indirectly tied to composition. For that purpose, the following analysis is performed.

\subsubsection{Deposit composition layering}

First, the thermal-conductivity radial profile in E155AB was obtained at each time as explained in Section 3 - Step 3b. In practice, the analysis can be made more efficient by analysing appropriately 
linearized segments of the curve in Figure 8 . The resulting conductivity radial profile at the end of the period is plotted against the deposit apparent thickness in Figure $9(\mathrm{a})$. Each $\left(\lambda_{1}-\delta_{\mathrm{a}}\right)$ point on the curve in this graph represents, for the corresponding time, the estimated local conductivity $\lambda_{l}$ of a new layer depositing on top of a deposit of thickness $\delta_{a}$. The profile in Figure 9(a) evidences more clearly some of the observations made earlier. A main, clearly distinguishable conductivity peak is observed for the portion of deposit formed during the acute fouling period. The conductivity of this thick portion is above $1.75 \mathrm{Wm}^{-1} \mathrm{~K}^{-1}$ and reaches a maximum of $2.8 \mathrm{Wm}^{-1} \mathrm{~K}^{-1}$, indicating high inorganic content. Moreover, two secondary peaks are observed which were formed before and after the main peak. Near the end of the period, a very low conductivity $\lambda_{l}=0.2-0.25 \mathrm{Wm}^{-1} \mathrm{~K}^{-1}$, indicating fresh organic deposition, is observed at the top of the layer, near its surface. This low conductivity sub-layer has an insulating effect, and significantly decreases the apparent conductivity of the deposit as a whole to the final value of 0.6$0.7 \mathrm{Wm}^{-1} \mathrm{~K}^{-1}$ noted in Figure 8 .

Next, this local conductivity profile was translated into a composition profile using suitable mixing rules and assumptions. In this case study, the deposit was assumed to be composed of two pseudocomponents, one organic and one inorganic (the latter representing the overall contribution of all inorganic species), each of constant thermal-conductivity. Based on the reported deposit composition (mainly $\mathrm{FeS}$ and $\mathrm{CaCO}_{3}$, Table 2), the conductivity of the inorganic portion is in the range $3-5 \mathrm{Wm}^{-}$ ${ }^{1} \mathrm{~K}^{-1}[30]$. Hence, an average conductivity $\lambda_{\text {inorg }}=4 \mathrm{Wm}^{-1} \mathrm{~K}^{-1}$ was assumed for the inorganic foulant. Given the relatively low temperature in this heat exchanger $\left(130-180^{\circ} \mathrm{C}\right.$ tube-side) and the time evolution of the apparent conductivity observed in , neglecting the impact of ageing on the thermalconductivity of the organic and inorganic portions is reasonable $[30,46]$, and a typical value $\lambda_{\text {org }}=0.2$ $\mathrm{Wm}^{-1} \mathrm{~K}^{-1}$ was assumed for the organic portion. Average density values for the organic and inorganic foulants (2360 $\mathrm{kg} \mathrm{m}^{-3}$ for asphalt and $3200 \mathrm{~kg} \mathrm{~m}^{-3}$ for inorganics, respectively) were assumed based on the literature [69-71] so as to convert mass fraction $(w)$ into volume fraction $(x)$.

Based on those assumptions, the fractions of inorganic and organic material at each point through the deposit were estimated using each of the four conductivity mixing models presented (Eqs. 4-7). The resulting radial profiles of the inorganic weight fraction are shown in Figure 9(b). With all mixing models, the peaks in conductivity are well matched by peaks in inorganics content, whilst the top portion 
of the layer is dominated by organic material. The main peak in conductivity is clearly highlighted as being dominated by inorganics deposition during the acute deposition period. The quantitative composition results are significantly affected by the conductivity mixing model used, as expected from Figure 2. Consistently with Figure 2, the linear model leads to the lowest inorganic content estimates, the ME model to the highest, and the CC and EMT models to intermediate values.

\subsection{Validation against experimental data}

As indicated earlier, deposit samples were collected at the end of the period studied from the tubes of exchanger E155AB. Samples for a partially overlapping period were also available from exchanger E155X, equivalent to E155AB but located in a parallel PHT in the same refinery and processing the same crude oil in approximately the same operating conditions.

Images of the deposits were shown in Figure 4 and some composition analysis data for E155A and E155B were reported in Table 2. The latter provided the opportunity for a direct validation of the deposit extent and properties estimated in the previous sections against the experimental characterisation of the collected deposits. Thermal conductivities of the samples were not available, but composition analysis was carried out, so the validation was performed in terms of composition.

\subsubsection{Homogenised samples}

Each of the deposits from E155A and E155B were fully mixed and homogenised during collection and any potential information about stratification was unfortunately lost. The quality of the composition estimates was therefore assessed by comparing the estimated inorganic weight fraction, calculated from averaging the radial composition profile estimated from the plant operating data at the end of run (Figure $9 b)$ with the overall experimental inorganic weight fraction of the scraped and homogenized samples. The experimental fraction used, 58.6 $\%$, shown in Table 4, is the average of the values measured in the tube-side deposits from E155A and E155B, reported in Table 2, while the difference between the two samples ( $61.7_{\mathrm{wt}} \%$ and $55_{\mathrm{wt}} \%$, respectively) gives some idea of the variability involved.

The estimated results are also shown in Table 4 for each of the 4 mixing models used. First, it is noted that all methods estimated a substantial inorganic content, and the experimental value lies within 
the range of predicted inorganic weight fractions. The average inorganic content estimated with the linear mixing model is $31.7_{\mathrm{wt}} \%$, under-predicting the experimental value, while the ME model average estimate $\left(67.8_{\mathrm{wt}} \%\right)$ over-predicts the inorganic content. The average inorganic content was estimated at $52_{\mathrm{wt}} \%$ and $49.5 \mathrm{wt} \%$ with CC and EMT, respectively. The CC mixing model seemingly provides the best agreement with the experimental value. There are clearly many possible sources of error, from deposit sampling and storage, to analytical, to those inherent in averaging a distribution, hence further validation is clearly required. Nonetheless the estimated results are well in the ballpark of the measured ones and represent, as far as we are aware, the first practical method for the identification of deposit composition from operation data, and the first use of a deposit structure model in the analysis of crude oil fouling deposits.

The time-variation of the deposit apparent conductivity estimated from the operating plant data provides a clear indication of the presence of layering due to changes in the nature of the material being deposited. As these two samples were homogenised on collection, a direct comparison of estimated vs. measured deposit composition history is not possible. However, an initial, qualitative, assessment is made in the following section.

\subsubsection{Stratified deposit samples}

Intact samples of fouling deposit still inside the tubes were available for exchanger E155X, equivalent to E155AB and operating in a parallel PHT in the same refinery, processing the same crude oil feedstock and operating in similar conditions. The integrity of the E155X samples, shown in Figure 4(d), enabled obtaining experimental radial concentration profiles of the deposit constituent species. However, the train where E155X is located has a different desalter (and desalter history). As also noted, these samples were collected during a shutdown that took place two years after the $2^{\text {nd }}$ shutdown of E155AB. In other words, only the last two years of operation of E155AB considered in this study overlapped with the initial two years of operation of E155X. The deposition histories on E155AB and E155X are therfore not directly comparable. Furthermore, a full set of operating data was not available for E155X, so our previous model-based analysis of its operating data could not be carried out. As a result, a direct validation of estimated and predicted radial composition was not possible. 
Nonetheless, a comparison of the predicted deposit composition profiles in E155AB with the experimental ones in E155X provides an initial indication of the ability of the dynamic, thermohydraulic analysis approach presented to describe and monitor observed characteristics of the fouling deposit.

\section{Experimental analysis}

Experimental compositional analysis of layered deposit from slices cut from a E155X tube enabled measuring radial concentration profiles at the corresponding axial location. The composition of nine species in the deposit $(\mathrm{Ca}, \mathrm{O}, \mathrm{Na}, \mathrm{Mg}, \mathrm{Si}, \mathrm{S}, \mathrm{Cl}, \mathrm{Ca}, \mathrm{Fe})$ was measured at various distances from the deposit surface along a radius by Scanning Electron Microscopy with Energy-Dispersive X-ray spectroscopy (SEM-EDX) for a tube slice (Sample 1). The detailed experimental procedure and analysis results are reported elsewhere [58]. The SEM image of the deposit is shown in Figure 10(a). Visually, some layering is evident. Labels s1 to s17 indicate the 17 points of analysis with EDX, which were taken every $200 \mu \mathrm{m}$. The EDX results are shown in Figure 10(b) as weight percent normalized with respect to the species analysed.

Although SEM-EDX is not aimed at providing accurate quantitative measurement of the local concentration, the \% weight radial profile of the 9 species was used to estimate the organic and inorganic fractions at each point through the deposit. It was assumed that: i) $\mathrm{Mg}$ and Ca were in the form of their corresponding carbonates; ii) the fraction of $\mathrm{C}$ in the organic and inorganic portions was estimated based on assumption i) above,; iii) $\mathrm{O}$ was mainly present in the inorganic portion (as carbonates, oxides, etc.); iv) the organic portion had a $\mathrm{H} / \mathrm{C}$ atomic ratio of 0.9 . The resulting inorganic content radial profile is shown in Figure 11(a). The figure shows an overall decrease in inorganic content in the radial direction from the wall to the surface and a single-point peak. This peak may be explained by high concentration of deposited $\mathrm{Fe}_{1-\mathrm{x}} \mathrm{S}$ particles, but other factors, such as the presence of a steel particle produced during the tube cutting process or surface irregularities could not be excluded. The calculated average inorganic content of Sample 1 is $46.9 \mathrm{wt} \%$.

From this experimental concentration profile and the thermal-conductivities of individual species, the corresponding local thermal-conductivity profile was evaluated (as detailed in section 2.3) using the EMT and CC models, the two conductivity mixing models providing the best match for the 
homogenized samples (previous section). The conductivity profiles obtained with the two models, shown in Figure 11(b), show very similar shapes and values ranging between 0.6-1.5 W/mK. They both reflect a peak in inorganics for deposits in the $\sim 0.6-1.0 \mathrm{~mm}$ layer, followed by a generally decreasing inorganics content in subsequent deposits, however with another, smaller peak in the layer being deposited at thicknesses of $\sim 2.4-2.6 \mathrm{~mm}$. The main difference is observed in the thermal conductivity at the peak, where the EMT model results in a maximum conductivity of $2.6 \mathrm{~W} / \mathrm{mK}$, while the CC model gives a maximum value of $1.7 \mathrm{~W} / \mathrm{mK}$.

The same experimental analysis was performed on a second tube slice sample (Sample 2) at a different axial location in the same tube. To check for azimuthal gradients, the EDX profile was developed at three angular locations (r1, r2 and r3). The resulting estimated local thermal-conductivity profiles are shown in Figure 12(a) and (b) for the CC and EMT mixing models, respectively. The shaded ribbon represents the range of values obtained for Sample 2 (S2) along the radial coordinate. The three radial profiles are in good agreement for most of the points sampled, as indicated by a narrow band in the shaded area. The deposit layer corresponding to thicknesses between $1.8-2.4 \mathrm{~mm}$ corresponds to points of high conductivity but inconsistently for the three locations, as indicated by the wide shaded area. In particular, one of the measurement at thickness $1.8 \mathrm{~mm}(\mathrm{~S} 2, \mathrm{r} 3$ in Figure $12 \mathrm{~b})$ seems to be an outlier. The general agreement in the analysis of the three radial locations and the similar thickness in the three cases supports the assumption of axisymmetric distribution made in the multicomponent, distributed deposit model [35].

The combined results from Sample 1 and Sample 2 (Figure 13) seem to indicate a peak of inorganics (hence thermal-conductivity) being deposited around the $\sim 1.8-2.2 \mathrm{~mm}$ layer, with a less pronounced peak at around the $\sim 0.8-1 \mathrm{~mm}$ layer.

\section{Experimental (E155X) and estimated (E155AB) profiles}

As mentioned previously, the local conductivity profiles in E155X (from the experimental EDX analysis, Figure 13) and E155AB (estimated from historical plant data, Figure 9a) cannot be compared. Nonetheless, the respective profiles in Figure 9(a) and Figure 13 allow some initial qualitative observations. 
Peaks in inorganics are noted in both curves. As discussed in [41], other factors could be responsible for the peaks which need to be investigated, including water and salt content in the crude oil leaving the desalter as well as the flow rates of water and caustic injected into crude oil at the entrance of theses PDPF exchangers. Outside the periods of peak inorganics deposition, conductivity values along the two deposits were remarkably similar, ranging between $0.5-1 \mathrm{~W} / \mathrm{mK}$. This suggests that the chronic fouling behaviour and the prevailing mechanisms in both units were most likely the same. The difference in the average experimental inorganic content estimated to be $58.6_{\mathrm{wt}} \%$ in E155AB vs $42.7_{\mathrm{wt}} \%$ in E155X (taking into account samples S1 and S2) could be explained by the different operating periods of the exchangers and/or the analytical procedures employed (loss on ignition test for the E155AB samples while EDX results for E155X). The linear and ME conductivity mixing models applied to Samples 1 and 2 result in values of conductivity for the E155X deposit significantly greater and lower than those in E155AB, respectively (not shown here). Consistently with the results for the homogenized sample, the EMT and CC models seem to provide the best agreement between the experimental characterization and the estimated results based on the plant data.

These observations provide an initial, albeit indirect, indication of the presented approach capability in estimating deposit layering due to inorganic deposition. Both experimental composition analysis and the model-based analysis show substantial deposit layering, with distinct compositions at different times. Both estimated and measured composition as well as thermal conductivity profiles show similar behaviour, with periods of high inorganics deposition followed by periods of more organics deposition. This illustrates the potential of the thermo-hydraulic analysis method presented. The method is verifiable in principle. A procedure for its validation is suggested comprising the following steps, for a given exchanger:

1. Select an operation period starting from cleaning to shutdown; carefully collect operating data for the period (temperature, flowrates and pressure drops).

2. At shutdown, extract one or more tubes (possible when re-bundling is performed) and carefully collect intact tube-side layered deposits; if possible, identify the deposit structure.

3. Carry out experimental composition analysis of the intact layered deposit to obtain radial profiles. 
4. Based on the deposit composition and structure, using the appropriate structural mixing model, calculate the "experimental" local thermo-conductivity radial profiles.

5. Perform a model-based analysis of the plant operating data using the approach presented. Obtain the corresponding estimated radial thermo-conductivity profiles and estimate total inorganics profiles.

6. Compare results from 4 and 5 on a local thermo-conductivity diagram.

\section{Conclusions}

A framework and full methodology for plant data analysis had been proposed by Diaz-Bejarano $e t$ al. [46] using advanced dynamic thermo-hydraulic models, to identify the underlying properties of fouling deposits. The authors also presented an industrial case study using the method in conjunction with a model-based "soft pressure drop sensor", in the absence of such measurements. The industrial case presented here extends and demonstrates the practical, full application of that methodology to an industrial case where, in addition to the usual flowrate and temperature measurements, tube-side pressure drop measurements were also available. This study focuses on the analysis of a problematic post-desalter, pre-flash drum heat exchanger unit. The exchanger had been reported to undergo severe fouling on the tube-side, with the deposit composed of $58.6_{\mathrm{wt}} \%$ of inorganic species including mainly $\mathrm{FeS}$ and $\mathrm{CaCO}_{3}$. A period of 1256 days between shutdowns was studied in detail.

The results demonstrate that substantial additional information is produced by combining data and model-based analysis as outlined in this approach, in particular regarding the detailed fouling state of an exchanger, thickness of deposits, effective conductivity of deposits, and radial profiles of deposit conductivity and composition, reflecting the exchanger past and current operation history. The outputs of this analysis highlight episodes of rapid and acute fouling, and deposition of inorganic materials. The information may be used in the diagnosis of the underlying causes leading to such events and for troubleshooting purposes.

The contribution of this work to the field of crude oil fouling relates to five main aspects: 
a) The combined application of thermo-hydraulic plant measurements to characterise the fouling state over time in terms of apparent thickness and conductivity, starting from the operational data.

b) Re-constructing local conductivity profile using a deposit model with the ability to track deposition history.

c) Translation of the conductivity profile thus obtained into estimated composition profiles, defined in terms of inorganic-organic binary mixtures, for which the novel use of several thermal-conductivity structural mixing models was proposed and tested.

d) Experimental composition analysis of tube-side fouling deposits collected at the end of the period, demonstrating in one case the substantial layering of inorganics in the deposit.

e) Validation of the proposed data and model-based analysis method by i) comparison of averaged predicted and experimental compositions in a mixed deposit sample collected at the end of the run, and ii) a preliminary comparison of the deposit predicted and experimental layering structure in similar exchangers. Both validation steps yielded surprisingly good agreement.

The methodology presented goes significantly beyond current industrial practices that base the analysis of fouling behaviour on the calculation of simple fouling thermal resistances.

First, the above dynamic fouling analysis was successfully applied to extract, directly from plant measurements, the time evolution of the apparent thickness and apparent thermal-conductivity, showing excellent agreement with the field observations upon heat exchanger dismantling at the end of the period. These time-profiles not only allow identifying periods of different thickness increase (as a result of processing oils with different fouling propensity, or processing conditions), but also give some deep insights into the deposition history. The time-profile of the apparent conductivity indicates the degree of heterogeneity of the deposit. A significant variation indicates a layering effect due to distinct fouling behaviour along the operation period. In such case, a more detailed, radially distributed model is used to work out a local conductivity profile by taking advantage of the full-time profiles of apparent thickness and conductivity. The latter may be linked to a rough compositional characterization if a suitable structural conductivity mixing model is available. Four methods were proposed for this purpose, each suitable for different characteristics of the deposit. 
In the industrial case at hand, the dynamic analysis of fouling state revealed a mixed inorganicorganic deposition mechanism with an acute inorganic deposition period after approximately 160 days. The results were compared to available experimental data, producing excellent results, providing preliminary verification of the thermo-hydraulic analysis method, and enabling testing of the various thermal-conductivity structural models introduced. Their choice seems to have an important effect on the results, with two of the models yielding better estimates of the composition measurements. The best agreement between the experimental characterization and the results based on plant data were obtained for a Co-continuous model, whilst the commonly used simple weighted average was found to be the model producing the poorest results.

Further validation against experimental data is no doubt required to establish with more confidence the ability of the method to estimate the profiles of conductivity and inorganics, and to confirm the conductivity mixing model that best represents heterogeneous crude oil fouling deposits. As discussed in ref. [44], the experimental compositional characterization of fouling deposit can vary with the analytical technique used. Therfore, for validation purposes there is a parallel need to develop more precise, comprehensive analysis protocols. Some work along such line is presented in ref. [58, 72].

The results presented provide solid evidence of the usefulness of analysing the entire history and evolution of the deposit to gain insights into the fouling mechanisms and their variation throughout the operating period. They demonstrate the ability to detect acute deposition periods and trace back their timing and likely composition for further investigation, therefore to detect and diagnose abnormal fouling behaviour, as discussed in a previous theoretical work [24]. Moreover, the results serve as motivation to introduce, where they are not present already, combined thermo-hydraulic measurements as a rich source of information for systematic performance monitoring of fouling processes. Finally, the results demonstrate the need and benefits of deposit models with the ability to track deposition history and their practical application to the analysis of deposits with complex layering structures. It is highlighted that the approach is not specific to crude oil fouling and could be applied to other industrial systems where deposit layering has been observed [73-76].

Overall, the results confirm that the method represents a new powerful, model-based tool to analyse a series of heat exchanger operational data and translate them into estimates of extent, characteristics 
(thermal conductivity and composition) and evolution of fouling deposits and the corresponding fouling rates over time, for monitoring, diagnosis and troubleshooting purposes.

\section{ACKNOWLEDGMENTS}

Initial methodological aspects of this research were partially performed under the UNIHEAT project, for which EDB and SM wish to acknowledge the Skolkovo Foundation and BP for financial support. EB and MRM wish to acknowledge EORC for the provision of case study data. Hexxcell Ltd. for the provision of Hexxcell Studio ${ }^{\mathrm{TM}}$ and the assistance of Pawel Orzlowski with some of the analytical work are also acknowledged.

\section{NOMENCLATURE}

$$
\begin{aligned}
& A \quad=\text { Flow area, } \mathrm{m}^{2} \\
& \text { API = API gravity, - } \\
& c=\text { Mass concentration, } \mathrm{kg} \mathrm{m}^{-3} \\
& \text { CC }=\text { Co-Continuous } \\
& C D U=\text { Crude distillation unit } \\
& C_{f} \quad=\text { Friction factor, }- \\
& C_{p} \quad=\text { Specific heat capacity, } \mathrm{J} \mathrm{kg}^{-1} \mathrm{~K}^{-1} \\
& D \quad=\text { Diameter, } \mathrm{m} \\
& \text { dir } \quad=\text { Direction of flow, }- \\
& \text { EMT = Effective media theory } \\
& h=\text { Heat transfer coefficient, } \mathrm{W} / \mathrm{m}^{2} \mathrm{~K} \\
& H \quad=\text { Specific enthalpy, } \mathrm{J} / \mathrm{kg} \\
& L \quad=\text { Tube length, } \mathrm{m} \\
& \dot{m} \quad=\text { Mass flowrate, } \mathrm{kg} / \mathrm{s} \\
& M E \quad=\text { Maxwell-Eucken } \\
& \text { MeABP = Mean average boiling point, }{ }^{\circ} \mathrm{C}
\end{aligned}
$$




$$
\begin{aligned}
& N C \quad=\text { Number of components } \\
& N_{p} \quad=\text { Number of passes } \\
& N R=\text { Number of reactions } \\
& N_{t} \quad=\text { Number of tubes } \\
& \text { PDPF } \quad=\text { Post-desalter, pre-flash drum } \\
& \text { PHT = Pre-heat train } \\
& p \quad=\text { Perimeter, } \mathrm{m} \\
& p_{i} \quad=\text { Inorganic-to-organic deposition rate ratio of component } i \\
& \operatorname{Pr} \quad=\text { Prandtl number } \\
& Q \quad=\text { Heat duty, } \mathrm{W} \\
& q^{\prime \prime} \quad=\text { Heat flux, } \mathrm{W} \mathrm{m}^{-2} \\
& R \quad=\text { Tube radius, } \mathrm{m} \\
& R_{\text {flow }} \quad=\text { Flow radius, } \mathrm{m} \\
& \text { Re } \quad=\text { Reynolds number } \\
& R_{f} \quad=\text { Fouling resistance, } \mathrm{m}^{2} \mathrm{~K} \mathrm{~W}^{-1} \\
& r \quad=\text { Radial coordinate, } \mathrm{m} \\
& \tilde{r}=\text { Dimensionless radial coordinate, }- \\
& r_{j} \quad=\text { Rate of reaction } \mathrm{j}, \mathrm{kg} \mathrm{m}^{-3} \mathrm{~s}^{-1} \\
& r 1, r 2, r 3=\text { Angular locations in Sample } 2 \\
& S 1, S 2=\text { Samples } 1 \text { and } 2 \\
& S E M-E D X=\text { Scanning Electron Microscopy with Energy-Dispersive X-ray } \\
& \text { spectroscopy } \\
& T=\text { Temperature, } \mathrm{K} \\
& t=\text { Time, } \mathrm{s} \\
& u=\text { Linear velocity, } \mathrm{m} / \mathrm{s} \\
& \text { VGO = Vacuum gas oil }
\end{aligned}
$$




$$
\begin{array}{ll}
x & =\text { Volume fraction, } \mathrm{m}^{3} \mathrm{~m}^{-3} \\
z & =\text { Axial coordinate, } \mathrm{m}
\end{array}
$$

\section{Greek letters}

$$
\begin{aligned}
\Delta P & =\text { Tube-side pressure drop, } \mathrm{Pa} \\
\delta_{l} & =\text { Fouling layer thickness, } \mathrm{m} \\
\dot{\delta}_{l} & =\text { Rate of change of fouling layer thickness, } \mathrm{m} \mathrm{s}^{-1} \\
\lambda & =\text { Thermal conductivity, } \mathrm{W} \mathrm{m}^{-1} \mathrm{~K}^{-1} \\
\mu & =\text { Dynamic viscosity, } \mathrm{Pa} \mathrm{s} \\
v_{38^{\circ} C} & =\text { Kinematic viscosity at } 38^{\circ} \mathrm{C}, \mathrm{mm} \mathrm{s}^{-1} \\
\rho & =\text { Density, } \mathrm{kg} \mathrm{m}^{-3} \\
\sigma & =\text { Standard deviation } \\
\tau_{w} & =\text { Wall shear stress (at deposit surface) }, \mathrm{N} \mathrm{m}^{-2} \\
\Omega & =\text { Spatial domain }
\end{aligned}
$$

\section{Subscripts}

$$
\begin{aligned}
a & =\text { Apparent } \\
\text { eff } & =\text { Effective } \\
f & =\text { Fouling } \\
\text { fresh } & =\text { Fresh, just settled deposit } \\
i & =\text { Component number, inner tube area } \\
\text { in } & =\text { Inlet } \\
\text { inorg } & =\text { Inorganic } \\
j & =\text { Reaction number } \\
l & =\text { Fouling layer } \\
n & =\text { Pass number } \\
o & =\text { Outer tube area } \\
\text { org } & =\text { Organic } \\
\text { out } & =\text { Outlet } \\
s & =\text { Shell-side } \\
t & =\text { Tube-side flow } \\
w & =\text { Tube wall }
\end{aligned}
$$




\section{References}

[1] F. Coletti, H. M. Joshi, S. Macchietto, and G. F. Hewitt, "Introduction to Crude Oil Fouling," in Crude Oil Fouling: Deposit Characterization, Measurements, and Modeling, F. Coletti and G. F. Hewitt, Eds. Boston: Gulf Professional Publishing, 2014.

[2] F. Coletti and S. Macchietto, "A Dynamic, Distributed Model of Shell-and-Tube Heat Exchangers Undergoing Crude Oil Fouling," Ind. Eng. Chem. Res., vol. 50, no. 8, pp. 45154533, Apr. 2011.

[3] S. Macchietto et al., "Fouling in Crude Oil Preheat Trains: A Systematic Solution to an Old Problem," Heat Transf. Eng., vol. 32, no. 3-4, pp. 197-215, Mar. 2011.

[4] H. Müller-Steinhagen, M. R. Malayeri, and A. P. Watkinson, "Heat Exchanger Fouling: Mitigation and Cleaning Strategies," Heat Transf. Eng., vol. 32, no. 3-4, pp. 189-196, Mar. 2011.

[5] F. Coletti and S. Macchietto, "Refinery Pre-Heat Train Network Simulation Undergoing Fouling: Assessment of Energy Efficiency and Carbon Emissions," Heat Transf. Eng., vol. 32, no. 3-4, pp. 228-236, Mar. 2011.

[6] M. Markowski, M. Trafczynski, and K. Urbaniec, "Identification of the influence of fouling on the heat recovery in a network of shell and tube heat exchangers," Appl. Energy, vol. 102, pp. 755-764, Feb. 2013.

[7] M. Yang and B. Crittenden, "Fouling thresholds in bare tubes and tubes fitted with inserts," Appl. Energy, vol. 89, no. 1, pp. 67-73, Jan. 2012.

[8] Y. Wang, M. Pan, I. Bulatov, R. Smith, and J.-K. Kim, “Application of intensified heat transfer for the retrofit of heat exchanger network," Appl. Energy, vol. 89, no. 1, pp. 45-59, Jan. 2012.

[9] M. Pan, I. Bulatov, and R. Smith, "Improving heat recovery in retrofitting heat exchanger networks with heat transfer intensification, pressure drop constraint and fouling mitigation," Appl. Energy, vol. 161, pp. 661-626, 2016.

[10] W. A. Ebert and C. B. Panchal, "Analysis of Exxon crude-oil-slip stream coking data," in Fouling Mitigation of Industrial Heat-Exchange Equipment, C. B. Panchal, Ed. San Luis Obispo, California (USA): Begell House, 1995, pp. 451-460.

[11] C. B. Panchal, W. C. Kuru, C. F. Liao, W. A. Ebert, and J. W. Palen, "Threshold conditions for crude oil fouling," in Understanding Heat Exchanger Fouling and its Mitigation, 1999, pp. 273-279.

[12] A. P. Watkinson and D. I. Wilson, "Chemical reaction fouling: A review," Exp. Therm. Fluid Sci., vol. 14, no. 4, pp. 361-374, May 1997.

[13] B. L. Yeap, D. I. Wilson, G. T. Polley, and S. J. Pugh, "Mitigation of crude oil refinery heat 
exchanger fouling through retrofits based on thermo-hydraulic fouling models," Chem. Eng. Res. Des., vol. 82, no. 1, pp. 53-71, 2004.

[14] G. T. Polley, D. I. Wilson, S. J. Pugh, and E. Petitjean, "Extraction of Crude Oil Fouling Model Parameters from Plant Exchanger Monitoring," Heat Transf. Eng., vol. 28, no. 3, pp. 185-192, Mar. 2007.

[15] M. Ratel, Y. Kapoor, Z. Anxionnaz-Minvielle, L. Seminel, and B. Vinet, "Investigation of fouling rates in a heat exchanger using an innovative fouling rig," in Proc. Int. Conf. Heat Exchanger Fouling and Cleaning - 2013, 2013, pp. 36-41.

[16] A. L. H. Costa et al., "Parameter Estimation of Fouling," Heat Transf. Eng., vol. 34, no. 8-9, pp. 683-691, 2013.

[17] B. D. Crittenden, S. T. Kolaczkowski, and I. L. Downey, "Fouling of Crude Oil Preheat Exchangers," Trans IChemE, Part A, Chem Eng Res Des, vol. 70, pp. 547-557, 1992.

[18] T. Takemoto, B. D. Crittenden, and S. T. Kolaczkowski, "Interpretation of fouling data in industrial shell and tube heat exchangers," Chem. Eng. Res. Des., vol. 77, no. 8, pp. 769-778, 1999.

[19] F. Coletti et al., "Modelling of Fouling from Molecular to Plant Scale," in Crude Oil Fouling: Deposit Characterization, Measurements, and Modeling, F. Coletti and G. F. Hewitt, Eds. Boston: Gulf Professional Publishing, 2014.

[20] R. C. Gunness and J. G. Baker, "Testing heat transfer equipment," Ind. Eng. Chem., vol. 30, no. 4, pp. 373-376, 1938.

[21] G. M. Jones and T. R. Bott, "Monitors and models for the assessment of petroleum fouling of refinery heat exchangers," in Proc. Int. Conf. Mitigation of Heat Exchanger Fouling and its Economic and Environmental Implications, July 18-23, 1999, Banff, Canada, 2001, pp. 59-69.

[22] N. F. Glen, J. H. Howarth, and A. M. Jenkins, "Fouling monitoring on process plant - field experience," in Int. Conf. Mitigation of Heat Exchanger Fouling and its Economic and Environmental Implications, July 18-23, 1999, Banff, Canada, 2001, pp. 70-76.

[23] A. Heins, R. Veiga, C. Ruiz, and A. Riera, "Fouling Monitoring and Cleaning Optimisation in a Heat Exchanger Network of a Crude Distallation Unit," Proc. 7th Int. Conf. Heat Exch. Fouling Clean. - Challenges Oppor., vol. RP5, no. 1925, 2007.

[24] A. Mirsadraee and M. R. Malayeri, "Analysis of Highly Noisy Crude Oil Fouling Data Using Kalman Filter," in Proc. Int. Conf. Heat Exchanger Fouling and Cleaning - 2015, 2015, pp. 97-103.

[25] F. Albert, W. Augustin, and S. Scholl, "Roughness and constriction effects on heat transfer in crystallization fouling," Chem. Eng. Sci., vol. 66, no. 3, pp. 499-509, 2011.

[26] D. I. Wilson and A. P. Watkinson, "A study of autoxidation reaction fouling in heat exchangers," Can. J. Chem. Eng., vol. 74, pp. 236-246, 1996.

[27] M. Turakhia, W. G. Characklis, and N. Zelver, "Fouling of Heat Exchanger Surface: 
Measurement and Diagnosis," Heat Transf. Eng., vol. 5, no. July 2015, pp. 93-101, 1984.

[28] ESDU, "Heat exchanger fouling in pre-heat train of a crude oil distillation unit, ESDU Data Item 00016," London, 2000.

[29] E. Diaz-Bejarano, F. Coletti, and S. Macchietto, "Crude oil Fouling Deposition, Suppression, Removal and Consolidation - and how to tell the difference," Heat Transf. Eng., vol. 38, no. 7-8, pp. 681-693, 2016.

[30] E. Diaz-Bejarano, F. Coletti, and S. Macchietto, "Impact of Complex Layering Structures of Organic and Inorganic Foulants on the Thermohydraulic Performance of a Single Heat Exchanger Tube: A Simulation Study," Ind. Eng. Chem. Res., vol. 55, no. 40, pp. 10718 10734, 2016.

[31] A. P. Watkinson, "Particulate Fouling of Sensible Heat Exchangers," University of British Columbia, 1968.

[32] A. P. Watkinson, "Critical Review of Organic Fluid Fouilng," 1988.

[33] A. P. Watkinson, "Chemical reaction fouling of organic fluids," Chem. Eng. Technol., vol. 15, no. 2, pp. 82-90, 1992.

[34] E. M. Ishiyama, F. Coletti, S. Macchietto, W. R. Paterson, and D. I. Wilson, "Impact of Deposit Ageing on Thermal Fouling: Lumped Parameter Model," AIChE J., vol. 56, no. 2, pp. 531-545, 2010.

[35] E. Diaz-Bejarano, F. Coletti, and S. Macchietto, "A new dynamic model of crude oil fouling deposits and its application to the simulation of fouling-cleaning cycles," AIChE J., vol. 62, no. 1, pp. 90-107, 2016.

[36] T. R. Bott, Fouling of Heat Exchangers, 1st ed. Amsterdam: Elsevier Science, 1995.

[37] J. F. Shackelford and W. Alexander, CRC Materials Science and Engineering Handbook, 3rd ed. London: CRC press, 2000.

[38] W. Wang and A. P. Watkinson, "Iron Sulphide and coke fouling from sour oils: review and initial experiments," in Int. conf. on heat exchanger fouling and cleaning 2011, 2011, vol. 2011, pp. 23-30.

[39] M. Srinivasan and a. P. Watkinson, "Fouling of Some Canadian Crude Oils," Heat Transf. Eng., vol. 26, no. 1, pp. 7-14, Jan. 2005.

[40] C. A. Bennett, R. S. Kistler, K. Nangia, W. Al-Ghawas, N. Al-Hajji, and A. Al-Jemaz, "Observation of an Isokinetic Temperature and Compensation Effect for High-Temperature Crude Oil Fouling," Heat Transf. Eng., vol. 30, no. 10-11, pp. 794-804, Sep. 2009.

[41] S. Venditti et al., "Developing Characterisation Methods for Foulants Deposited in Refinery Heat Exchangers," in International Conference on Heat Exchanger Fouling and Cleaning VIII, 2009, pp. 44-51.

[42] A. Young et al., "Characterization of Crude Oils and Their Fouling Deposits Using a Batch Stirred Cell System,” Heat Transf. Eng., vol. 32, no. 3-4, pp. 216-227, Mar. 2011. 
[43] M. R. Mozdianfard and E. Behranvand, "A field study of fouling in CDU preheaters at Esfahan refinery," Appl. Therm. Eng., vol. 50, no. 1, pp. 908-917, Jan. 2013.

[44] M. R. Mozdianfard and E. Behranvand, "Fouling at post desalter and preflash drum heat exchangers of CDU preheat train," Appl. Therm. Eng., vol. 89, pp. 783-794, 2015.

[45] H. M. Joshi, “Analysis of Field Fouling Deposits from Crude Heat Exchangers," in Crude Oil Fouling: Deposit Characterization, Measurements, and Modeling, F. Coletti and G. F. Hewitt, Eds. Boston: Gulf Professional Publishing, 2014.

[46] E. Diaz-Bejarano, F. Coletti, and S. Macchietto, "Thermo-Hydraulic Analysis of Refinery Heat Exchangers Undergoing Fouling,” AIChE J., vol. 63, no. 3, pp. 984-1001, 2017.

[47] Hexxcell Ltd., "Hexxcell Studio," 2017. [Online]. Available: http://www.hexxcell.com.

[48] E. Diaz-Bejarano and F. Coletti, "Modelling of Shell-side Crude Oil Fouling in Shell-andTube Heat Exchangers," in Int. conf. on heat exchanger fouling and cleaning 2015, 2015, pp. $81-88$.

[49] J. K. Carson, "Review of effective thermal conductivity models for foods," Int. J. Refrig., vol. 29, no. 6, pp. 958-967, 2006.

[50] J. Wang, J. K. Carson, M. F. North, and D. J. Cleland, "A new structural model of effective thermal conductivity for heterogeneous materials with co-continuous phases," Int. J. Heat Mass Transf., vol. 51, no. 9-10, pp. 2389-2397, May 2008.

[51] M. F. R. Mulcahy, J. Boow, and P. R. C. Goard, "Fireside Deposits and their Effect on Heat Transfer in a Pulverized-fuel-fired Boiler, Part I: The Radiant Emittance and Effective Thermal Conductance of the Deposits," J. Inst. Fuel, vol. 39, pp. 388-396, 1966.

[52] J. Boow and P. R. C. Goard, "Fireside Deposits and their Effect on Heat Transfer in a Pulverized-fuel-fired Boiler, Part IIII: The influence of the Physical Characteristics of the Deposit on its Radiant Emittance and Effective Thermal Conductance," J. Inst. Fuel, vol. 42, pp. 412-418, 1969.

[53] D. W. Anderson, R. Viskanta, and F. P. Incropera, "Effective Thermal Conductivity of Coal Ash Deposits at Moderate to High Temperatures," J. Eng. Gas Turbines Power, vol. 109, no. April, pp. 215-221, 1987.

[54] H. R. Rezaei et al., "Thermal conductivity of coal ash and slags and models used," Fuel, vol. 79, no. 13, pp. 1697-1710, 2000.

[55] T. Stephenson et al., "Thiophene mitigates high temperature fouling of metal surfaces in oil refining," Fuel, vol. 139, pp. 411-424, 2015.

[56] F. Coletti, E. M. Ishiyama, W. R. Paterson, D. I. Wilson, and S. Macchietto, "Impact of Deposit Aging and Surface Roughness on Thermal Fouling : Distributed Model," AIChE J., vol. 56, no. 12, pp. 3257-3273, 2010.

[57] N. Epstein, "Thinking about Heat Transfer Fouling: A 5 × 5 Matrix," Heat Transf. Eng., vol. 4, no. 1, pp. 43-56, 1983. 
[58] E. Behranvand, M. R. Mozdianfard, E. Diaz-Bejarano, F. Coletti, P. Orzlowski, and S. Macchietto, "Cross Sectional Examination of a Fouled Tube Removed from a Crude Oil Preheat Exchanger," Submitt. Publ., 2017.

[59] G. A. Lambourn and M. Durrieu, "Fouling in Crude Preheat Trains," in Heat Exchangers Theory and Practice, J. Taborek, G. F. Hewitt, and N. Afgan, Eds. New York: Hemisphere Publishing Company, 1983, pp. 841-850.

[60] M. R. Riazi, Characterization and properties of petroleum fractions, 1st ed. Philadelphia: ASTM, 2005.

[61] W. L. Nelson, "Fouling of heat exchangers," Refin. Nat. Gasol. Manuf., vol. 13, no. 7, pp. 271-276, 1939.

[62] G. T. Atkins, "What to do about high coking rates," Petro/Chem Eng., vol. 34, no. 4, pp. 20 25, 1962.

[63] B. D. Crittenden and S. T. Kolaczkowski, "Energy savings through the accurate prediction of heat transfer fouling resistances," in Energy for industry, O'Callaghan P. W., Ed. Oxford: Pergamon Press, 1979, pp. 257-266.

[64] E. M. Ishiyama, W. R. Paterson, and D. I. Wilson, "Optimum cleaning cycles for heat transfer equipment undergoing fouling and ageing," Chem. Eng. Sci., vol. 66, no. 4, pp. 604-612, Feb. 2011.

[65] T. Pogiatzis, E. M. Ishiyama, W. R. Paterson, V. S. Vassiliadis, and D. I. Wilson, "Identifying optimal cleaning cycles for heat exchangers subject to fouling and ageing," Appl. Energy, vol. 89, no. 1, pp. 60-66, Jan. 2012.

[66] L. Liu, J. Fan, P. Chen, J. Du, and F. Yang, "Synthesis of Heat Exchanger Networks Considering Fouling, Aging, and Cleaning," Ind. Eng. Chem. Res., vol. 54, no. 1, pp. 296-306, 2015.

[67] A. L. Diaby, S. J. Miklavcic, S. Bari, and J. Addai-Mensah, "Evaluation of crude oil heat exchanger network fouling behavior under aging conditions for scheduled cleaning," Heat Transf. Eng., vol. 37, no. 15, pp. 1211-1230, 2016.

[68] L. Lanchas-Fuentes, E. Diaz-Bejarano, F. Coletti, and S. Macchietto, "Management of Cleaning Types and Schedules in Refinery Heat Exchangers," in 12th International Conference on Heat Transfer, Fluid Mechanics and Thermodynamics, 2016.

[69] H. A. Nasr-El-Din and A. Y. Al-Humaidan, "Iron Sulfide Scale : Formation, Removal and Prevention," in SPE International Symposium on Oilfield Scale, 2001.

[70] A. C. J. Korte and H. J. H. Brouwers, "Calculation of thermal conductivity of gypsum plasterboards at ambient and elevated temperature," Fire Mater., vol. 34, pp. 55-75, 2010.

[71] F. Coletti, "Multi-scale Modelling of Refinery Pre-heat trains undergoing fouling for improved energy efficiency,” Imperial College London, 2010.

[72] E. Behranvand, M. R. Mozdianfard, E. Diaz-Bejarano, F. Coletti, P. Orzlowski, and S. 
Macchietto, "Investigating Refinery Preheaters Foulant Samples Originated by VGO and VB as Heating Fluids," Prep., 2017.

[73] A. Zbogar, F. Frandsen, P. A. Jensen, and P. Glarborg, "Shedding of ash deposits," Prog. Energy Combust. Sci., vol. 35, no. 1, pp. 31-56, 2009.

[74] F. Brahim, W. Augustin, and M. Bohnet, "Numerical simulation of the fouling process," Int. J. Therm. Sci., vol. 42, no. 3, pp. 323-334, Mar. 2003.

[75] V. Francia, L. Martin, A. E. Bayly, and M. J. H. Simmons, "The Role of Wall Deposition and Re-Entrainment in Swirl Spray Dryers,” AIChE J., vol. 61, no. 6, pp. 1804-1821, 2015.

[76] C. Henry and J.-P. Minier, "Progress in particle resuspension from rough surfaces by turbulent flows," Prog. Energy Combust. Sci., vol. 45, pp. 1-53, 2014.

[77] J. P. Holman, Heat transfer, 8th ed. London: McGraw-Hill, 2001.

[78] E. A. D. Saunders, Heat exchangers: Selection, Design, and Construction. Longman, Harlow, 1988.

[79] J. Taborek, "Shell-and-tube heat exchangers: single phase flow," in Heat Exchanger Design Handbook, G. F. Hewitt, Ed. New York: Begell House, 2002. 
Table 1. Main equations of the heat exchanger model by Coletti and Macchietto [2]

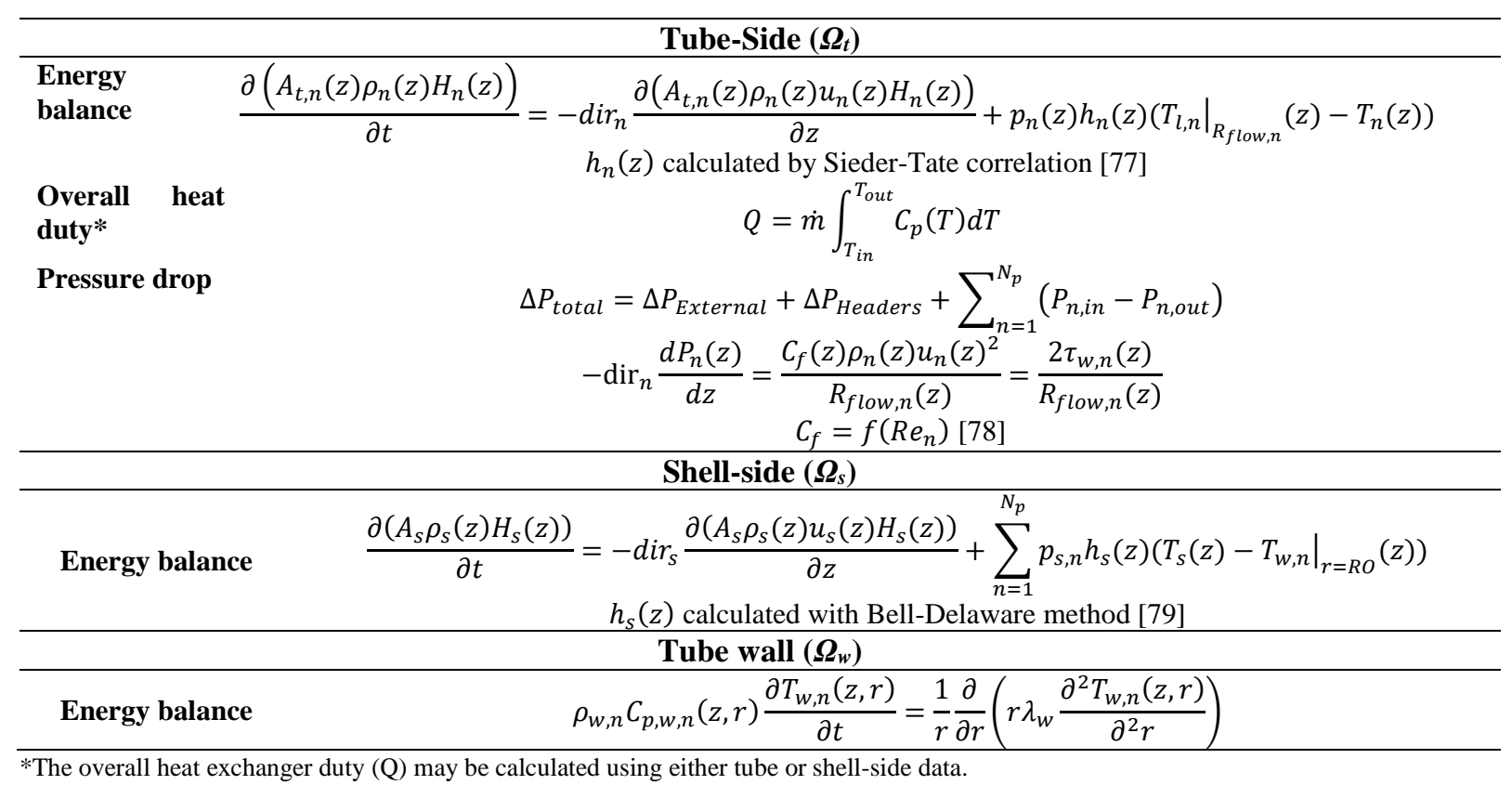


Table 2. Characteristics and analysis of deposits sampled in the $2^{\text {nd }}$ shutdown [44], [58]

\begin{tabular}{clll}
\hline & \multicolumn{1}{c}{ Tube-side } & \multicolumn{1}{c}{ Shell-side } \\
\hline State before cleaning & $\mathrm{E} 155 \mathrm{~A}$ & $\mathrm{E} 155 \mathrm{~B}$ & \\
$\%_{\mathrm{wt}}$ Organics & 38.3 & 44.5 & 30 \\
$\%_{\mathrm{wt}}$ Asphaltenes & 0.74 & 0.91 & - \\
$\%_{\mathrm{wt}}$ Inorganics & 61.7 & 55 & 70 \\
Inorganic species & $\mathrm{FeS}_{2}, \mathrm{CaCO}_{3}$ & $\mathrm{FeS}_{2}, \mathrm{Fe}_{0.95} \mathrm{~S}, \mathrm{CaCO}_{3}$ & $\mathrm{FeS}$ \\
Observed thickness $(\mathrm{mm})$ & $\mathrm{Not}$ reported. Thickness in equivalent unit in a parallel & $\approx 0.5 \mathrm{~mm}$ \\
& $\mathrm{PHT} \approx 2.5-3.2 \mathrm{~mm}$. In Figure 4 (d) thickness $\approx$ tube & \\
& wall (2.77 mm for 1" $\left.\mathrm{D}_{\mathrm{o}}\right)$ & & completely clean \\
\hline
\end{tabular}


Table 3. Main geometric parameters for E155AB.

\begin{tabular}{lllll}
\hline Parameter & Value & Parameter & $\begin{array}{l}\text { Tube-side } \\
\text { fluid }\end{array}$ & $\begin{array}{l}\text { Shell-side } \\
\text { fluid }\end{array}$ \\
\hline $\mathbf{N}_{\mathbf{s}}$ & 2 & Fluid & Crude Oil & VGO \\
Arrangement & Counter-current flow & API & 33.88 & 23.36 \\
Pass & 2 & MeABP $\left({ }^{\circ} \mathrm{C}\right)$ & 221.3 & 412.3 \\
$\mathbf{D}_{\mathbf{s}}(\mathbf{m m})$ & 1194 & $v_{38^{\circ} \mathrm{C}}(\mathrm{cSt})$ & 6 & 50 \\
$\boldsymbol{D}_{\boldsymbol{o}}(\mathbf{m m})$ & 19.86 & & & \\
$\boldsymbol{D}_{\boldsymbol{i}}(\mathbf{m m})$ & 25.4 & & & \\
$\mathbf{N}_{\mathbf{t}}$ & 844 & & & \\
\hline
\end{tabular}


Table 4. Experimental and estimated inorganic content in E155AB tube-side deposits

\begin{tabular}{lll}
\hline Method & $\begin{array}{l}\text { Conductivity } \\
\text { model }\end{array}$ & \% wt Inorganics \\
\hline Experimental & & $58.6^{*}$ \\
\hline Estimated & Linear & 31.7 \\
& EMT & 49.5 \\
& $\mathrm{CC}$ & 52.0 \\
& $\mathrm{ME}$ & 67.8 \\
\hline
\end{tabular}

*Average between the values reported for E155A and E155B in Table 2. 
Figure 1: Schematic representation of the modelling framework (adapted from [32], [43])

Figure 2: Effective conductivity estimated with several mixing models for binary mixtures of organic $\left(\lambda=0.2 \mathrm{Wm}^{-1} \mathrm{~K}^{-1}\right)$ and inorganic material $\left(\lambda=4 \mathrm{Wm}^{-1} \mathrm{~K}^{-1}\right)$.

Figure 3: Network structure after overhaul with available measurements (a) and timeline of events (b) (adapted from [40]).

Figure 4: Scraped tube-side deposit for hotter shell E155A (a), colder shell E155B (b), shell-side deposit (c), and in-tube deposit from unit E155X in a parallel PHT (d).

Figure 5: Heat duty (based on tube-side data) (a) and tube-side pressure drop (b) for exchanger E155AB.

Figure 6: Apparent thickness over time calculated daily (a) and 40-day centred moving average (b). Error bars in (b) represent $\pm 2 \sigma$.

Figure 7: Apparent conductivity over time calculate daily (a) and 40-day centred moving average (b). Error bars in (b) represent $\pm 2 \sigma$.

Figure 8: Apparent conductivity vs. apparent thickness profile.

Figure 9: Radial profiles at the end of the period: local conductivity (a) and inorganic content (calculated with various conductivity mixing models) (b).

Figure 10: Deposit from exchanger E155X, Sample 1: SEM Image (a); EDX elemental analysis (b). Labels s1(1-17) indicate the points of analysis with EDX in the radial direction, from the tube wall to the deposit surface.

Figure 11: Deposit from exchanger E155X, Sample 1: Estimated fraction (\% weight) of inorganic material (a) and corresponding local conductivity radial profile calculated with CC and EMT models (b).

Figure 12: Deposit from exchanger E155X, Sample 2: Estimated local conductivity radial profile at three angular locations (r1, r2, r3) calculated with CC (a) and EMT models (b).

Figure 13: Deposit from exchanger E155X, Sample 1 and 2: Estimated local conductivity radial profile calculated with CC (a) and EMT models (b). 


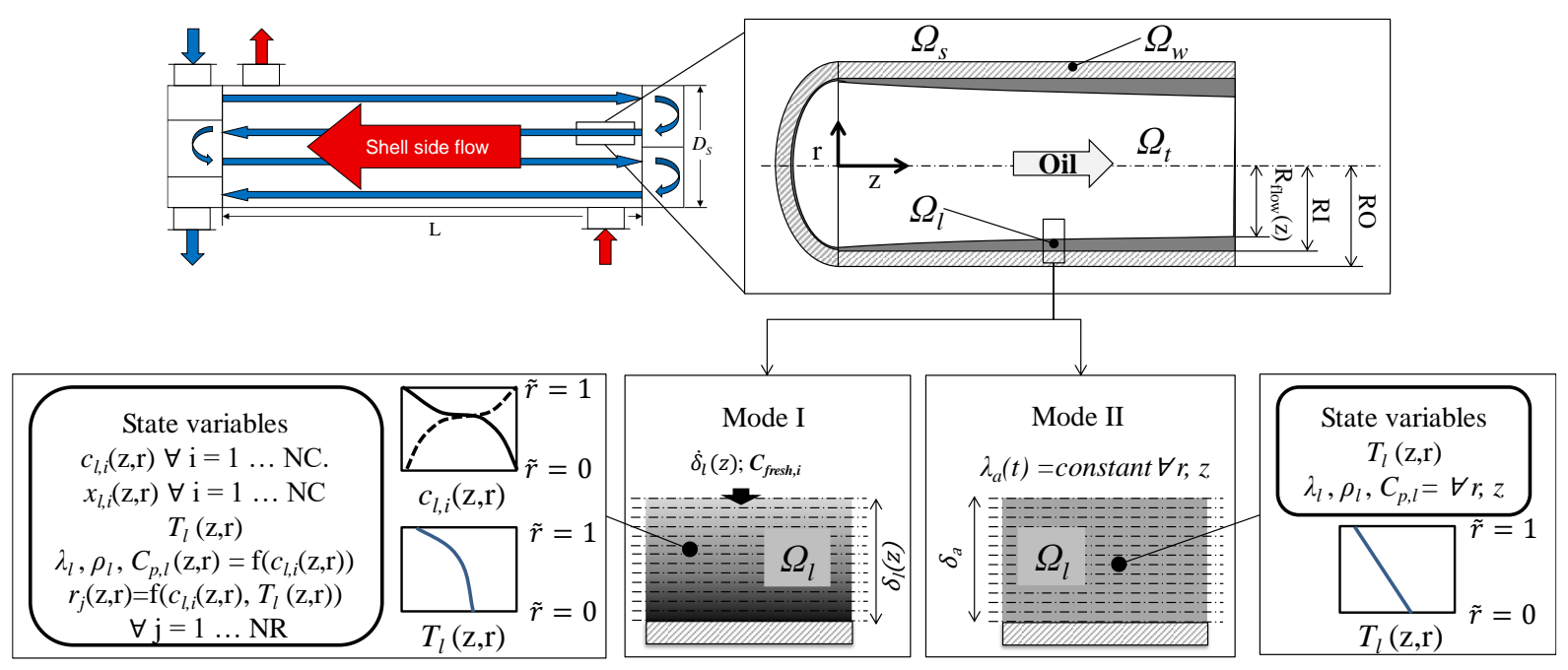

Figure 1: Schematic representation of the modelling framework (adapted from [35], [46]) 


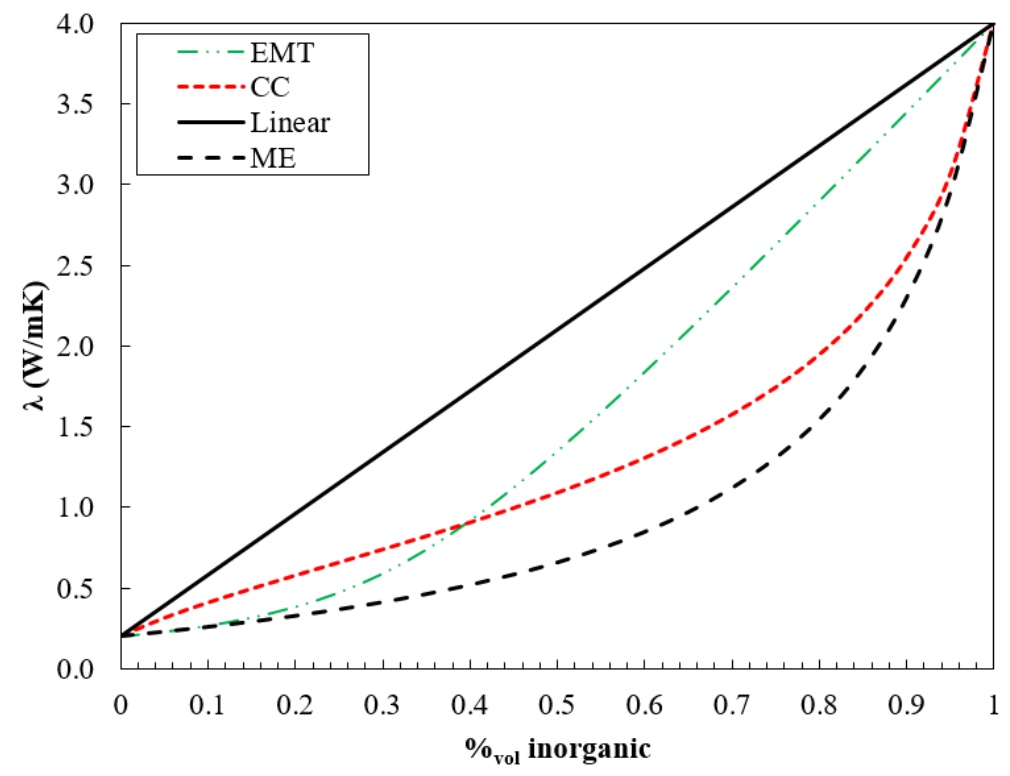

Figure 2: Effective conductivity estimated with several mixing models for binary mixtures of organic $\left(\lambda=0.2 \mathrm{Wm}^{-1} \mathrm{~K}^{-1}\right)$ and inorganic material $\left(\lambda=4 \mathrm{Wm}^{-1} \mathrm{~K}^{-1}\right)$. 


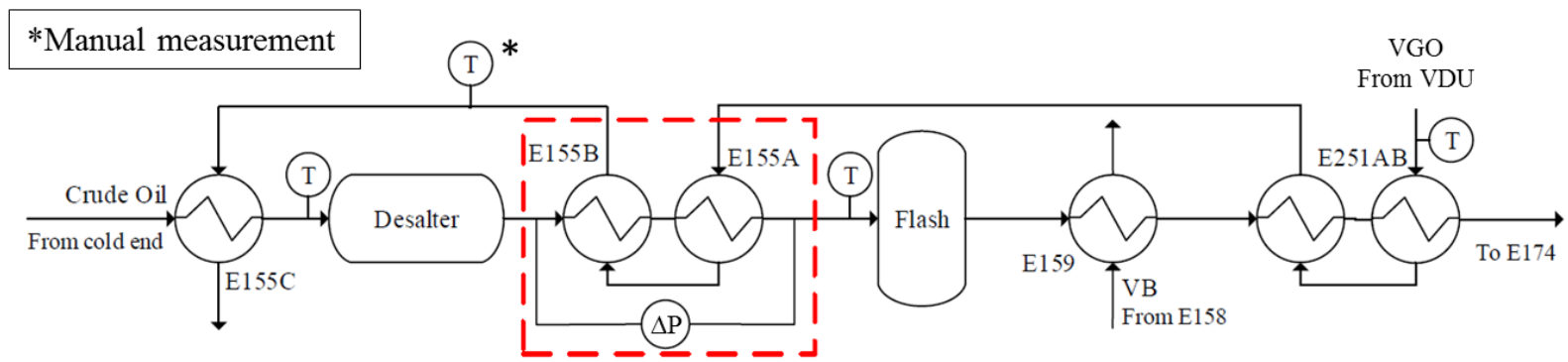

(a)

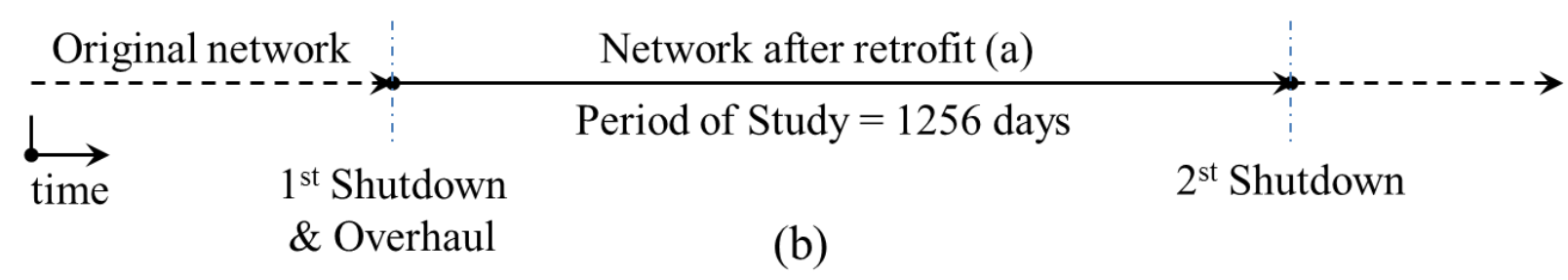

Figure 3: Network structure after overhaul with available measurements (a) and timeline of events (b) (adapted from [43]). 


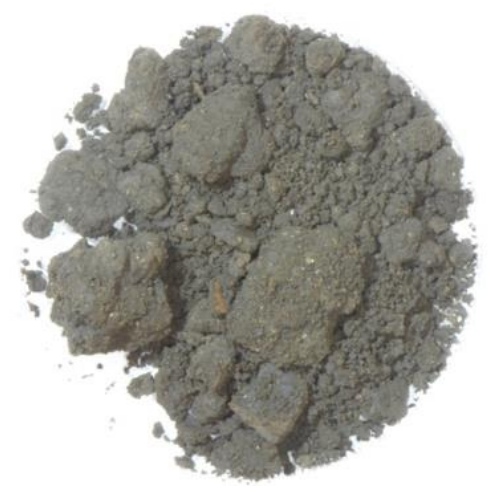

(a)

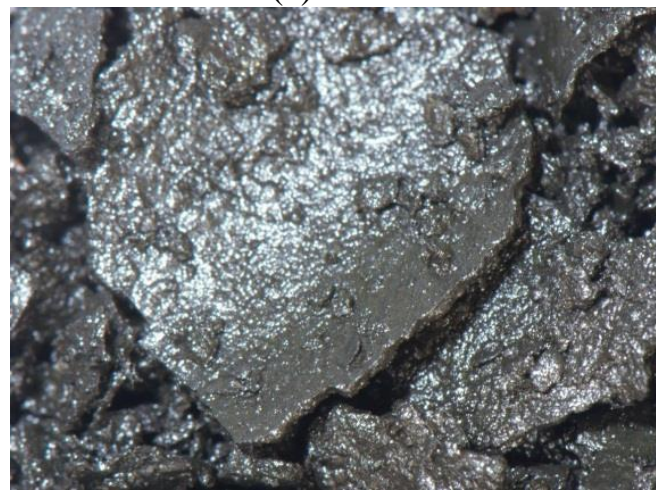

(c)

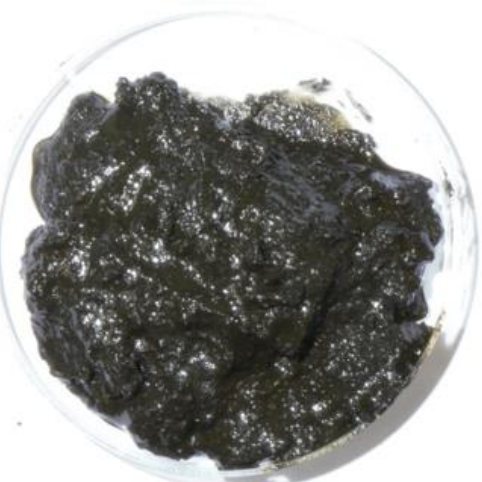

(b)

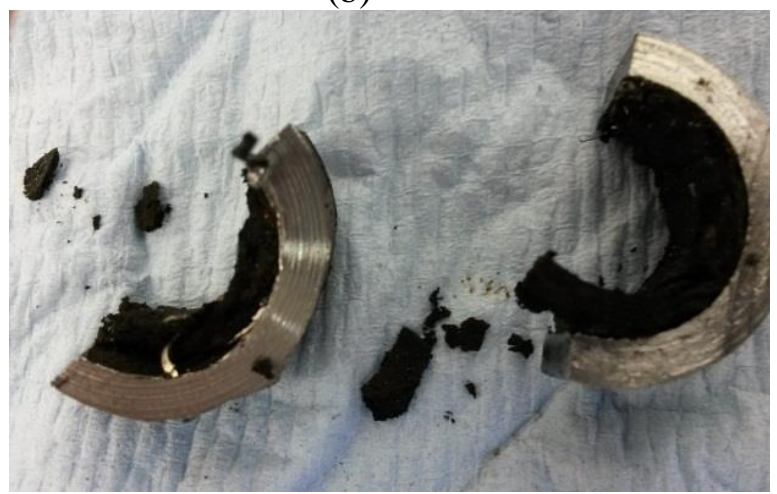

(d)

Figure 4: Scraped tube-side deposit for hotter shell E155A (a), colder shell E155B (b), shell-side deposit (c), and in-tube deposit from unit E155X in a parallel PHT (d). 


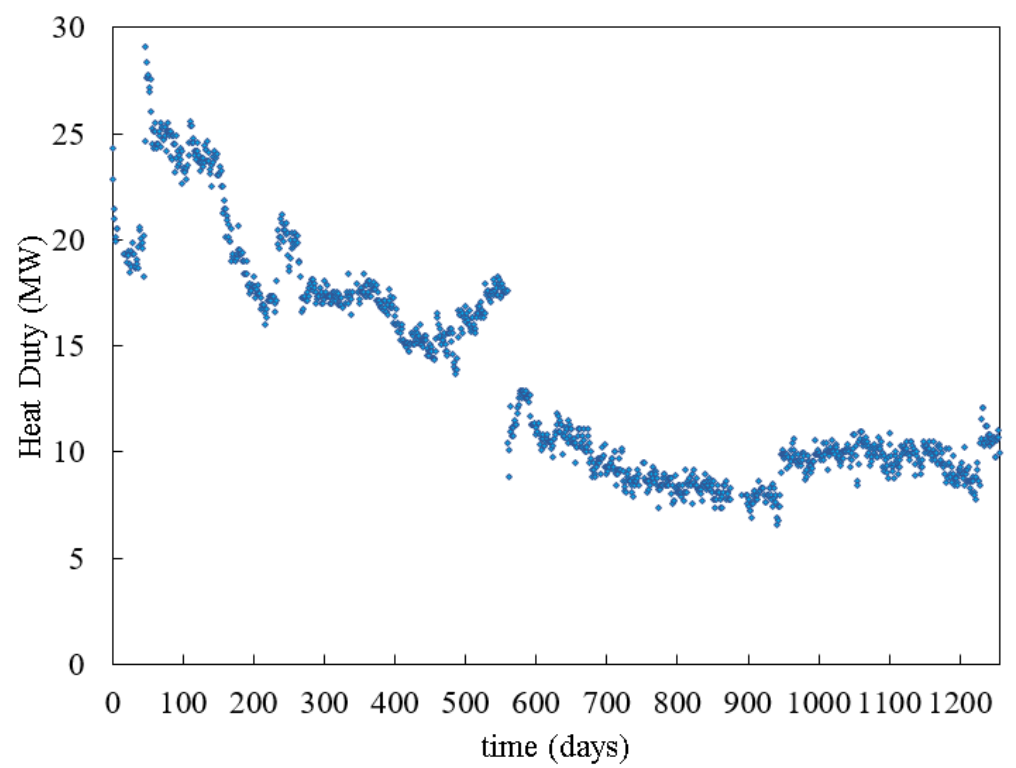

(a)

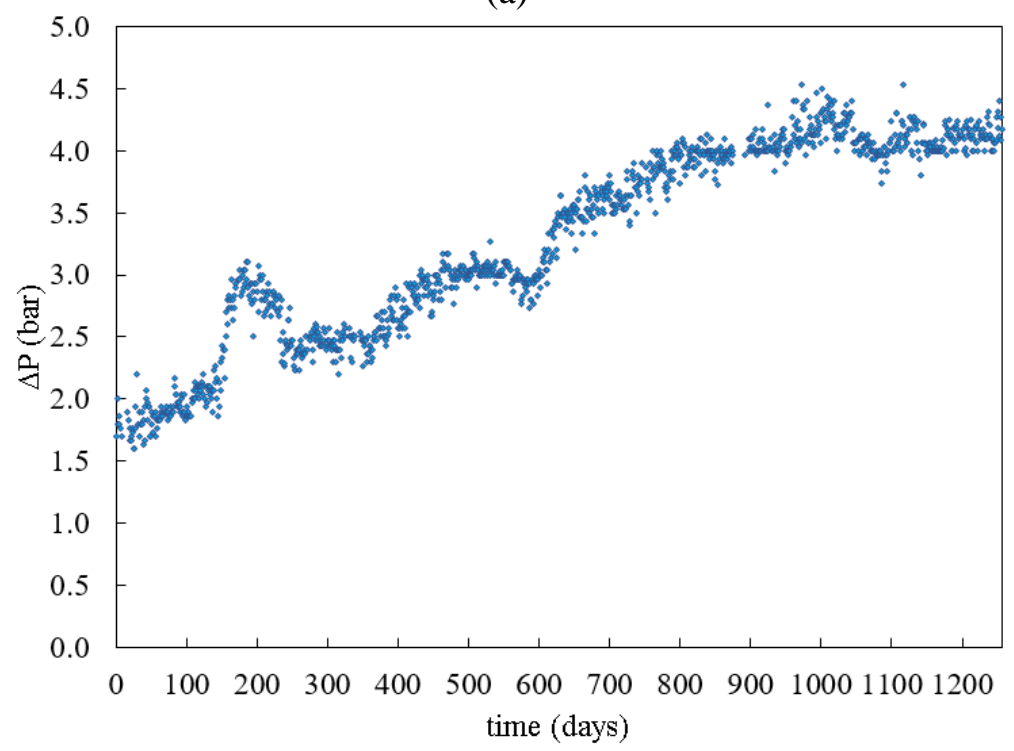

(b)

Figure 5: Heat duty (based on tube-side data) (a) and tube-side pressure drop (b) for exchanger E155AB. 

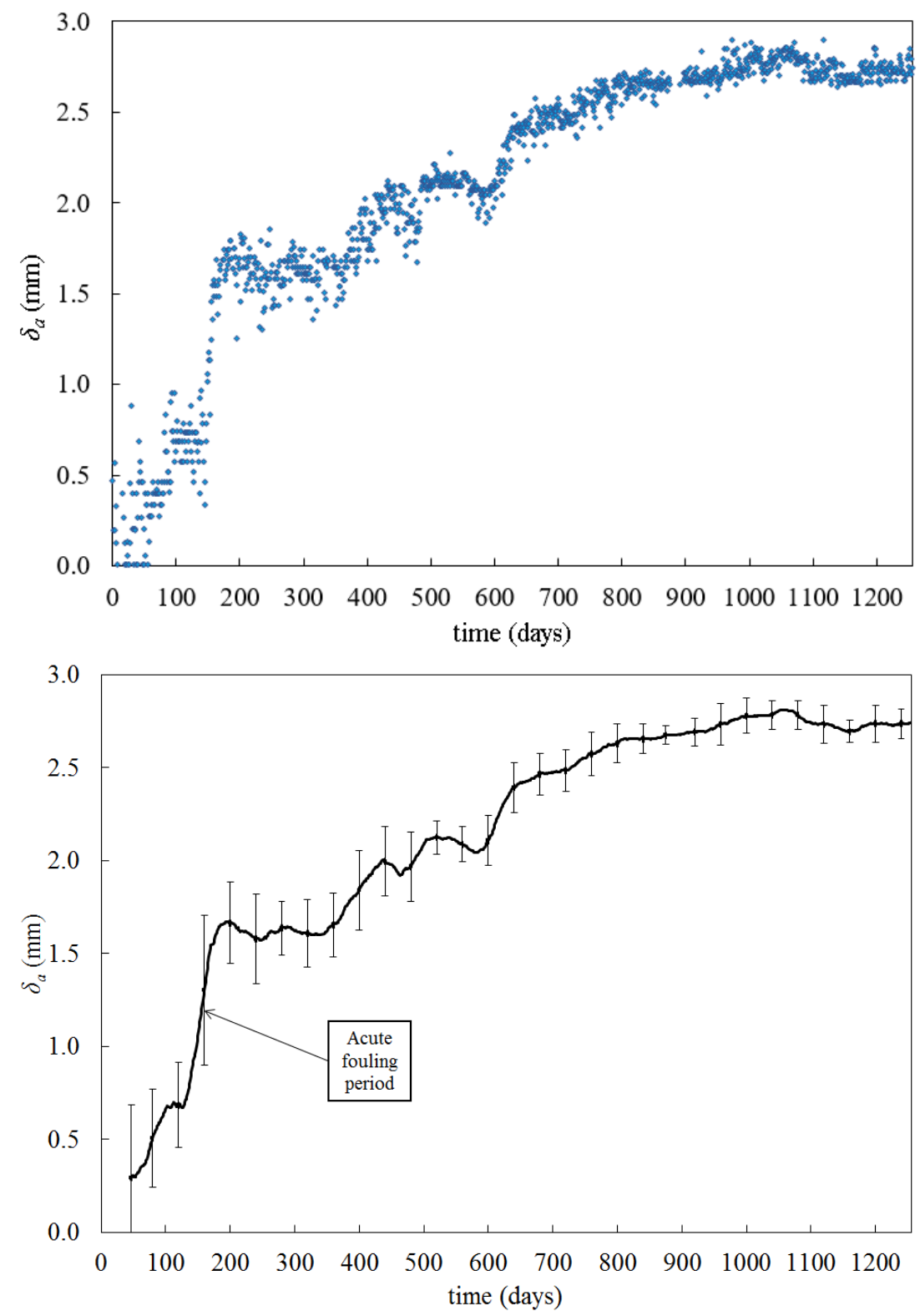

Figure 6: Apparent thickness over time calculated daily (a) and 40-day centred moving average (b). Error bars in (b) represent $\pm 2 \sigma$. 

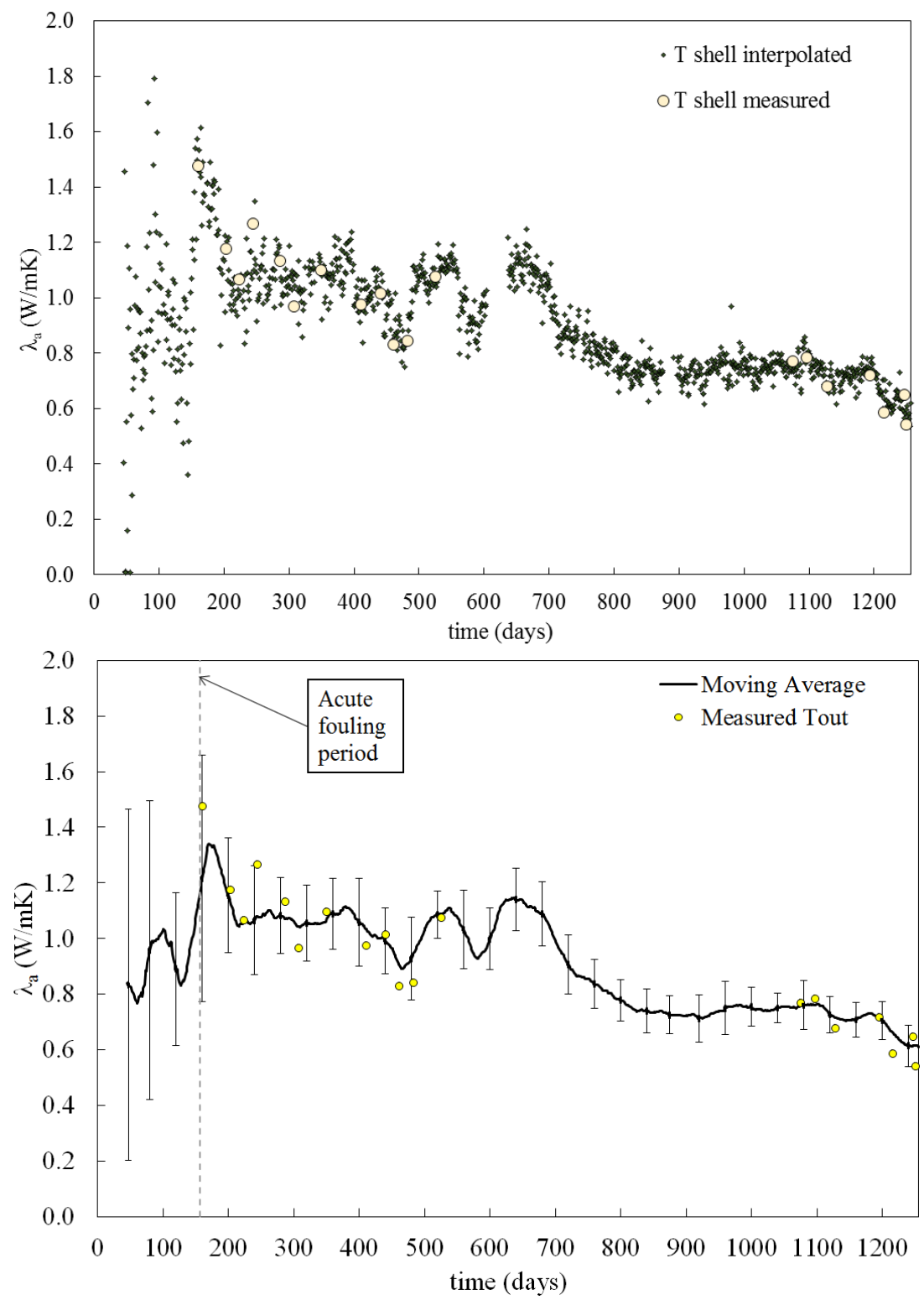

Figure 7: Apparent conductivity over time calculate daily (a) and 40-day centred moving average (b).

Error bars in (b) represent $\pm 2 \sigma$. 


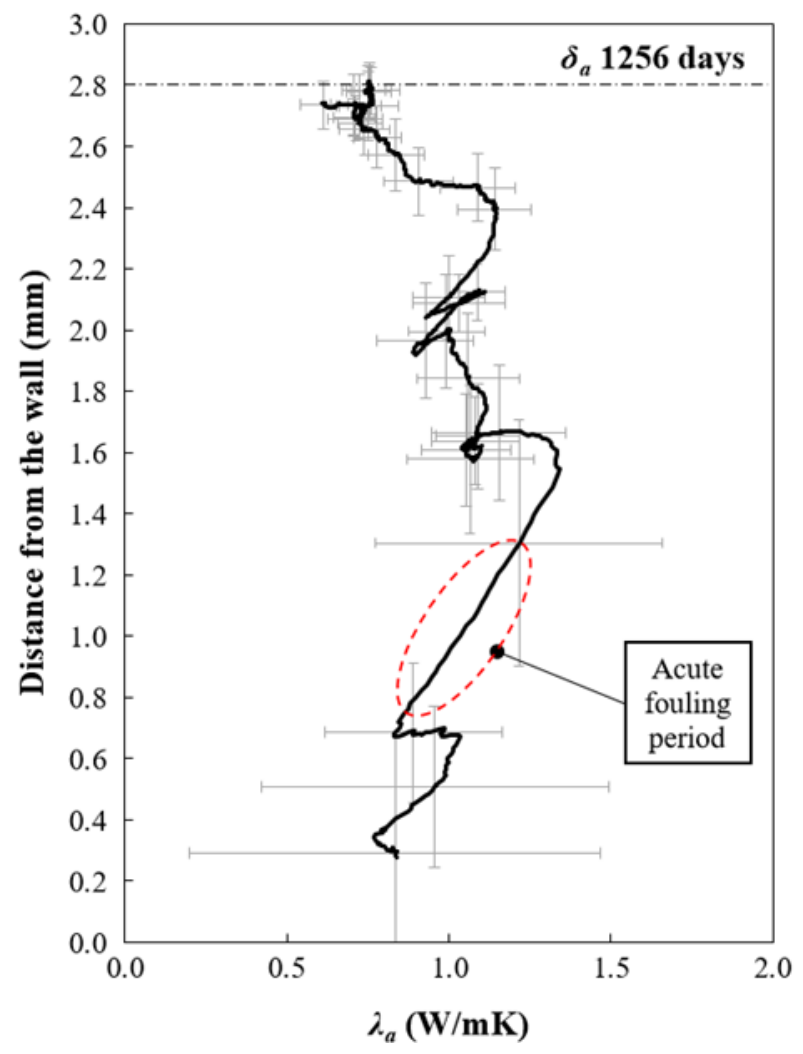

Figure 8: Apparent conductivity vs. apparent thickness profile. 

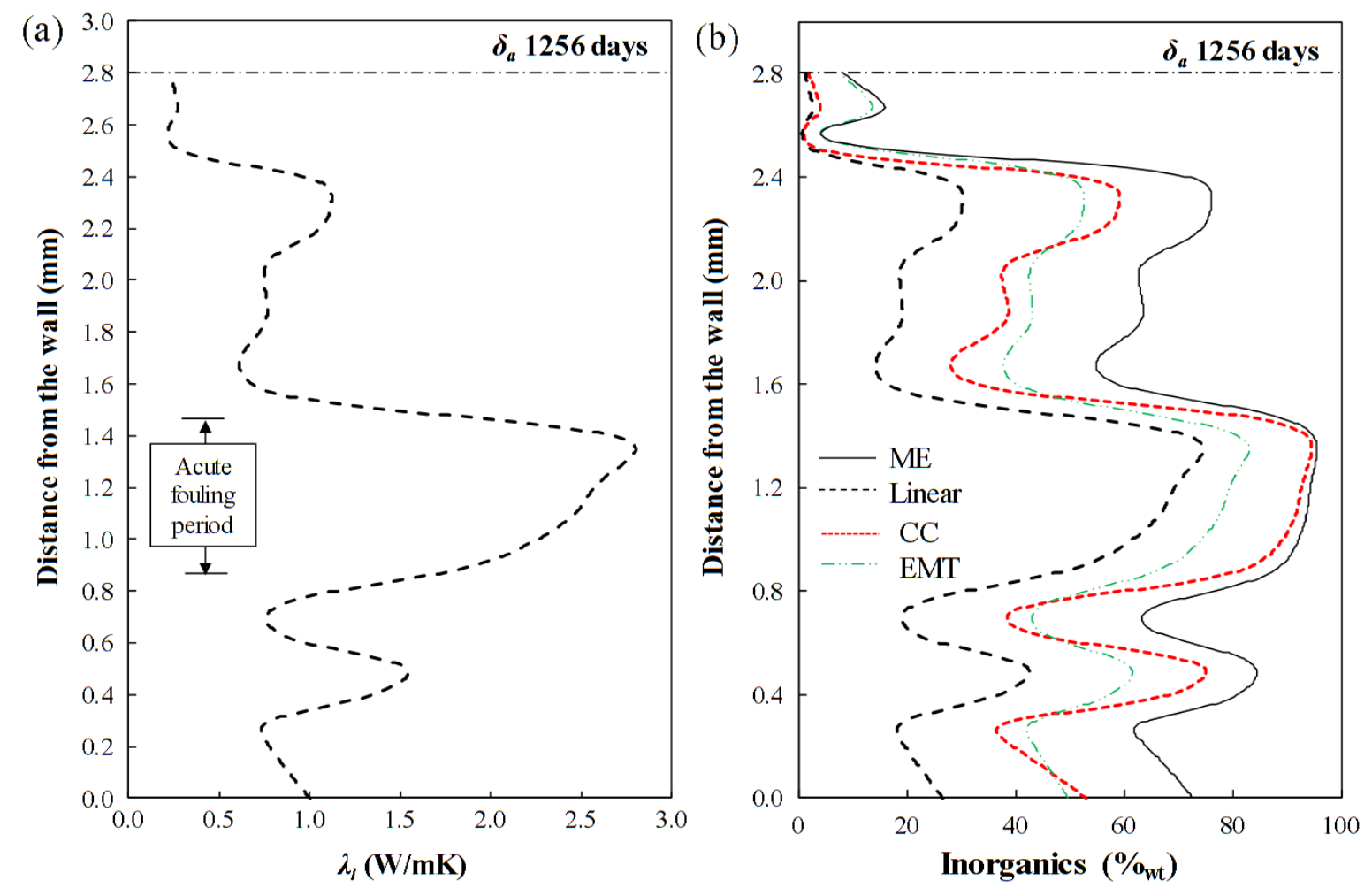

Figure 9: Radial profiles at the end of the period: local conductivity (a) and inorganic content (calculated with various conductivity mixing models) (b). 


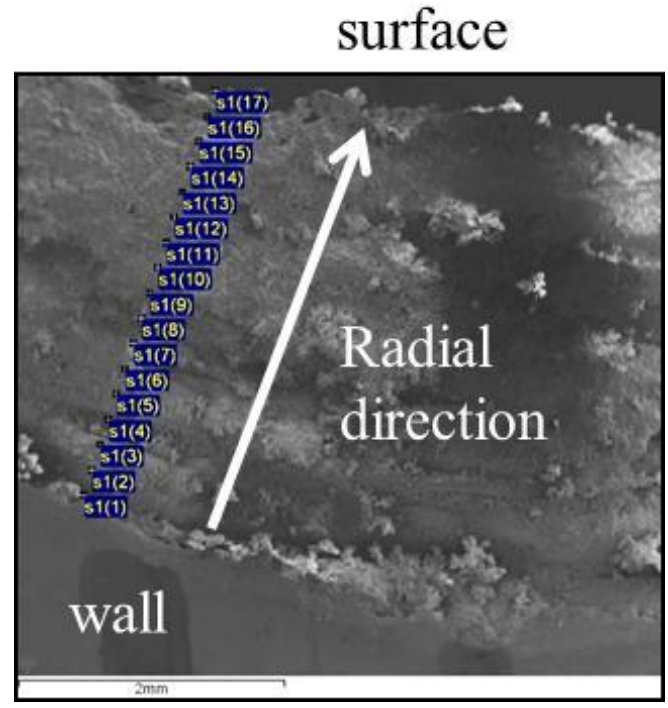

(a)

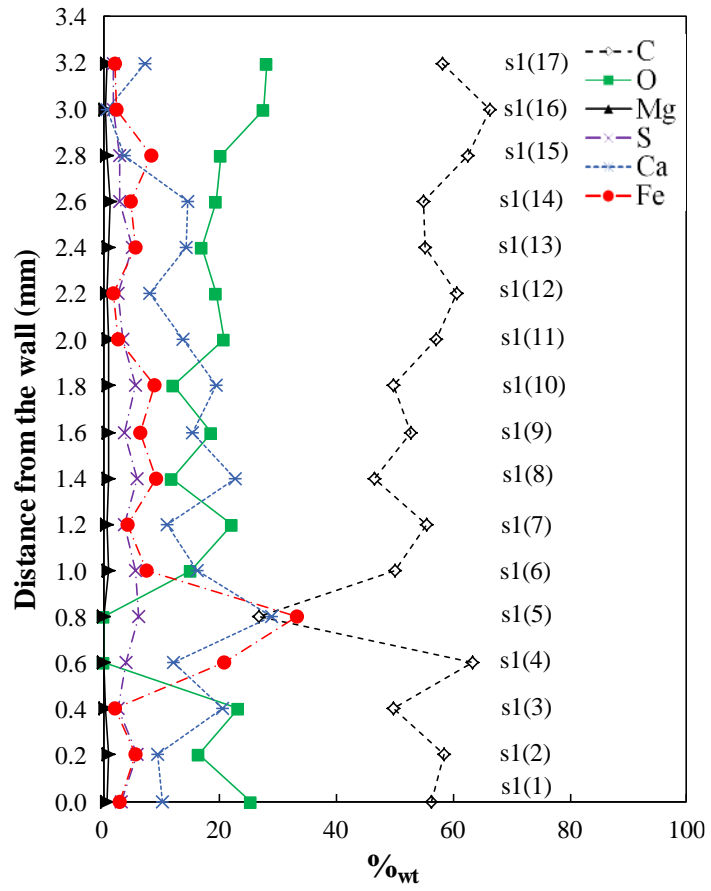

(b)

Figure 10: Deposit from exchanger E155X, Sample 1: SEM Image (a); EDX elemental analysis (b). Labels s1(1-17) indicate the points of analysis with EDX in the radial direction, from the tube wall to the deposit surface. 

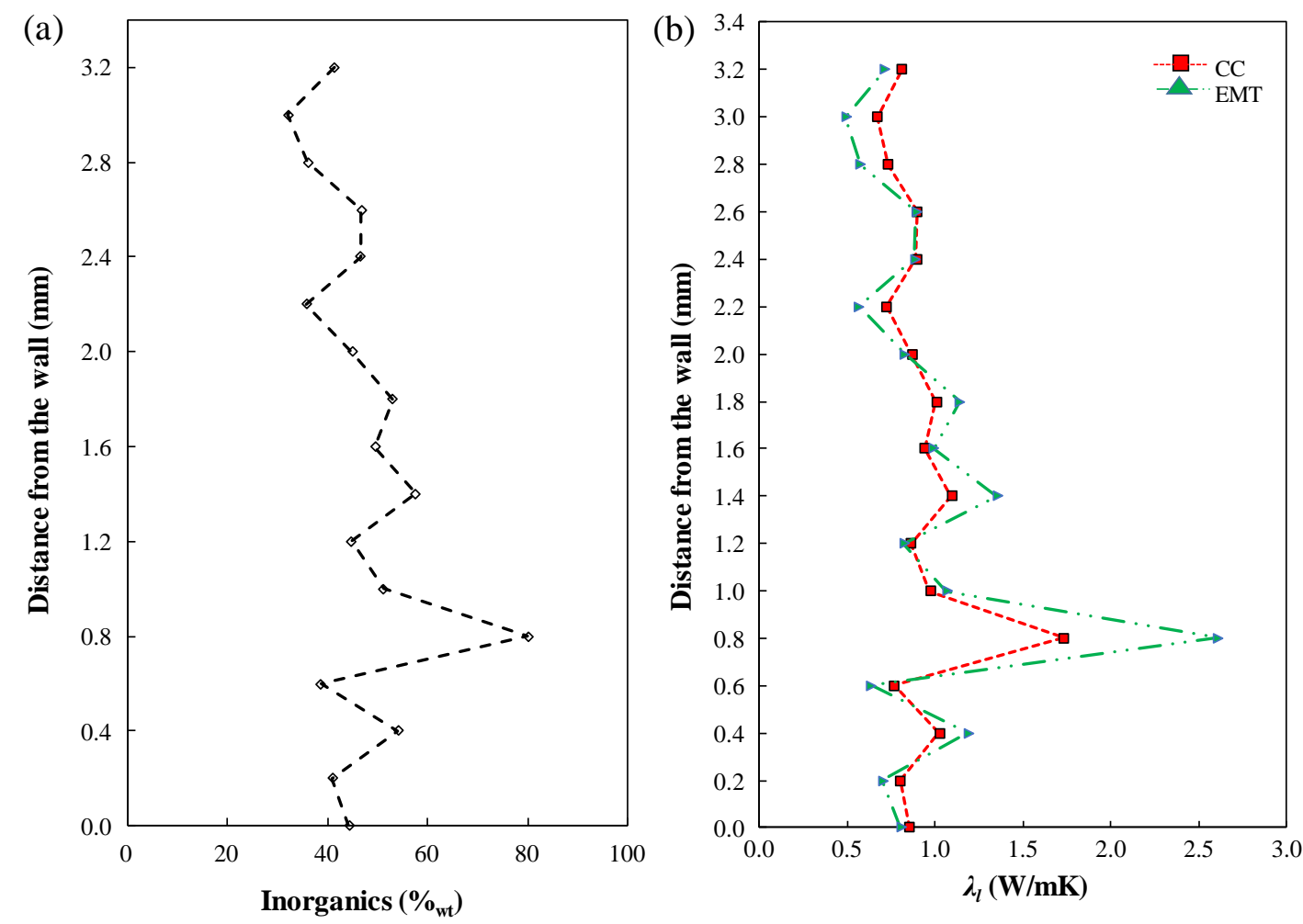

Figure 11: Deposit from exchanger E155X, Sample 1: Estimated fraction $\left(\%_{\mathrm{wt}}\right)$ of inorganic material (a) and corresponding local conductivity radial profile calculated with CC and EMT models (b). 

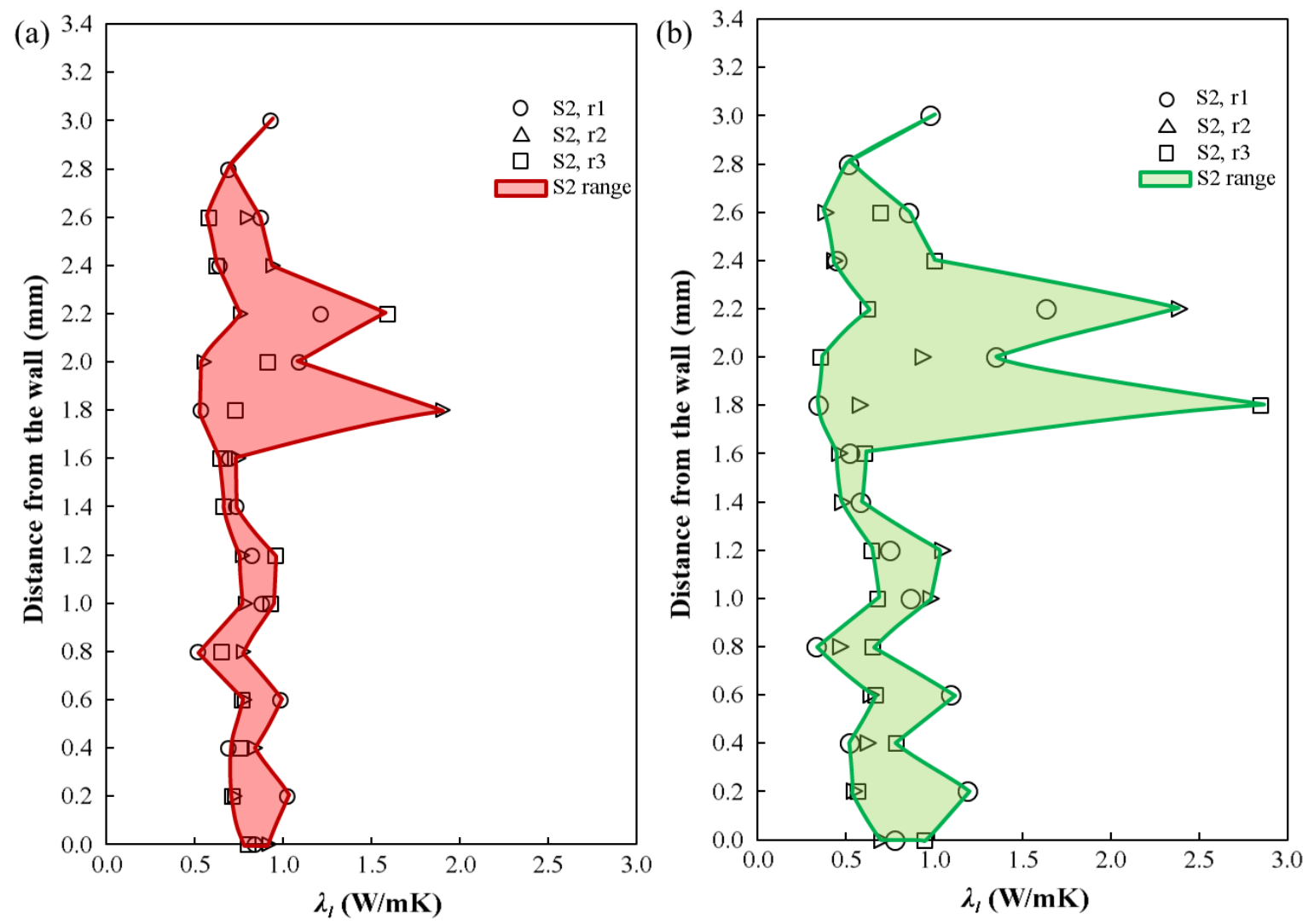

Figure 12: Deposit from exchanger E155X, Sample 2: Estimated local conductivity radial profile at three angular locations (r1, r2, r3) calculated with CC (a) and EMT models (b). 

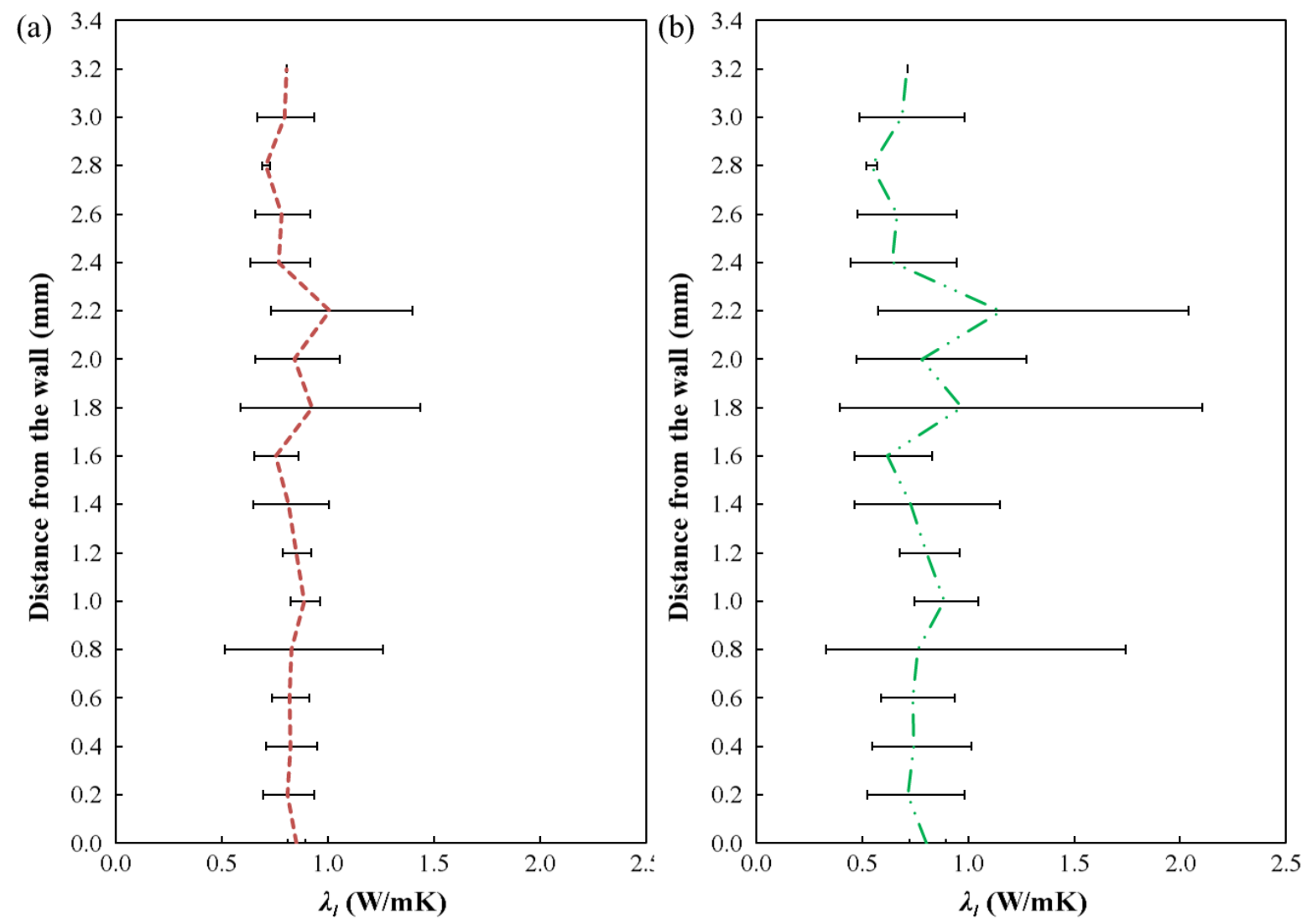

Figure 13: Deposit from exchanger E155X, Sample 1 and 2: Estimated local conductivity radial profile calculated with CC (a) and EMT models (b). 